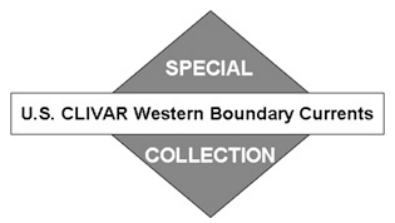

\title{
Western Boundary Currents and Frontal Air-Sea Interaction: Gulf Stream and Kuroshio Extension
}

\author{
Kathryn A. Kelly, ${ }^{*}$ R. Justin Small, ${ }^{+}$R. M. SAmelson, ${ }^{\#}$ Bo QiU, ${ }^{@}$ Terrence M. Joyce, \& \\ YOUNG-OH KWON, \& AND MEGHAN F. CRONIN** \\ * University of Washington, Seattle, Washington \\ ${ }^{+}$Jacobs Technology, Naval Research Laboratory, Stennis Space Center, Mississippi \\ \# COAS, Oregon State University, Corvallis, Oregon \\ ${ }^{\circledR}$ University of Hawaii at Manoa, Honolulu, Hawaii \\ ${ }^{\&}$ WHOI, Woods Hole, Massachusetts \\ ** NOAA/PMEL, Seattle, Washington
}

(Manuscript received 13 July 2009, in final form 11 February 2010)

\begin{abstract}
In the Northern Hemisphere midlatitude western boundary current (WBC) systems there is a complex interaction between dynamics and thermodynamics and between atmosphere and ocean. Their potential contribution to the climate system motivated major parallel field programs in both the North Pacific [Kuroshio Extension System Study (KESS)] and the North Atlantic [Climate Variability and Predictability (CLIVAR) Mode Water Dynamics Experiment (CLIMODE)], and preliminary observations and analyses from these programs highlight that complexity. The Gulf Stream (GS) in the North Atlantic and the Kuroshio Extension (KE) in the North Pacific have broad similarities, as subtropical gyre WBCs, but they also have significant differences, which affect the regional air-sea exchange processes and their larger-scale interactions. The 15-yr satellite altimeter data record, which provides a rich source of information, is combined here with the longer historical record from in situ data to describe and compare the current systems. While many important similarities have been noted on the dynamic and thermodynamic aspects of the time-varying GS and KE, some notso-subtle differences exist in current variability, mode water properties, and recirculation gyre structure. This paper provides a comprehensive comparison of these two current systems from both dynamical and thermodynamical perspectives with the goal of developing and evaluating hypotheses about the physics underlying the observed differences, and exploring the WBC's potential to influence midlatitude sea-air interaction. Differences between the GS and KE systems offer opportunities to compare the dominant processes and thereby to advance understanding of their role in the climate system.
\end{abstract}

\section{Introduction}

In the strong Northern Hemisphere midlatitude western boundary current (WBC) systems- - the Gulf Stream (GS) in the North Atlantic and the Kuroshio Extension (KE) in the North Pacific-there is a complex interaction between dynamics and thermodynamics and between the atmosphere and ocean (Fig. 1). A precipitous drop in the meridional transport of heat in the Northern Hemisphere ocean occurs where these warm WBCs separate from the coast and flow into the ocean interior (Trenberth and

Corresponding author address: Kathryn A. Kelly, P.O. Box 355640, Applied Physics Laboratory, University of Washington, Seattle, WA 98195-5640.

E-mail: kkelly@apl.washington.edu
Caron 2001). The ocean's heat is fluxed to the atmosphere through turbulent exchanges that fuel intense cyclogenesis over the regions (Hoskins and Hodges 2002; Nakamura et al. 2004; Bengtsson et al. 2006).

Recent interest in observed interannual-to-decadal climate variations and the midlatitude ocean's role in the climate system suggests the need for a better understanding of the mechanisms responsible for air-sea interaction over WBCs. For example, variations in the GS and KE currents and in air-sea heat fluxes have been shown to be related to the dominant climate indices in each ocean, for example, the Pacific decadal oscillation (PDO) and the North Atlantic Oscillation (NAO; see Joyce et al. 2000; Qiu 2003; Kelly and Dong 2004; DiNezio et al. 2009). Further, a recent analysis of the Community Climate System Model, version 2 (CCSM2) has shown that interannual variations 
(a) Topography and Mean SSH: NP

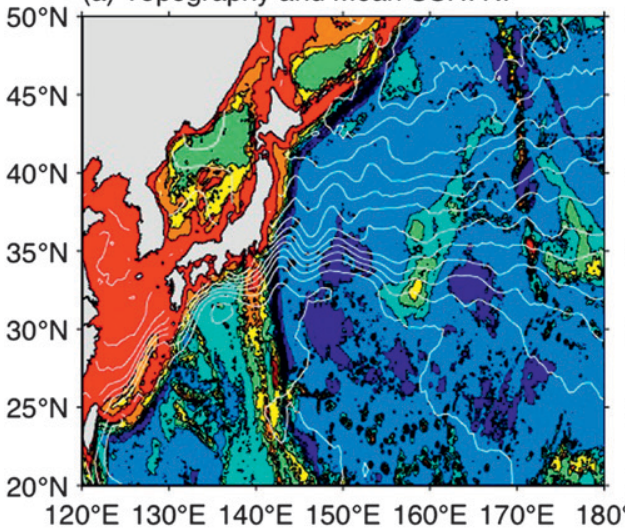

(b) RMS amplitude of SSH variability: NP

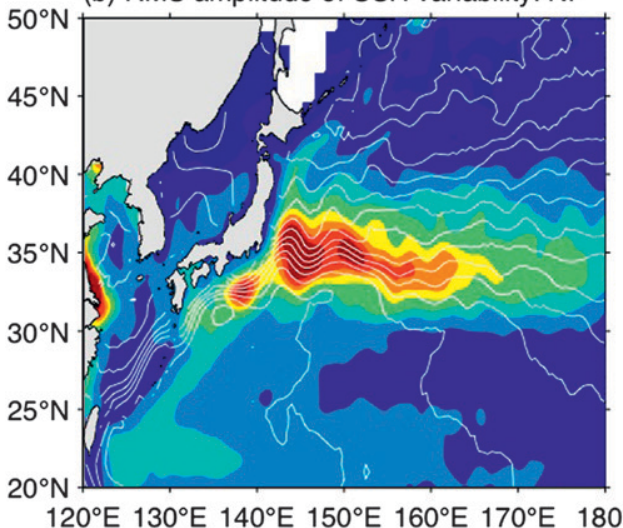

(c) STD of JFM Turbulent Flux: NP

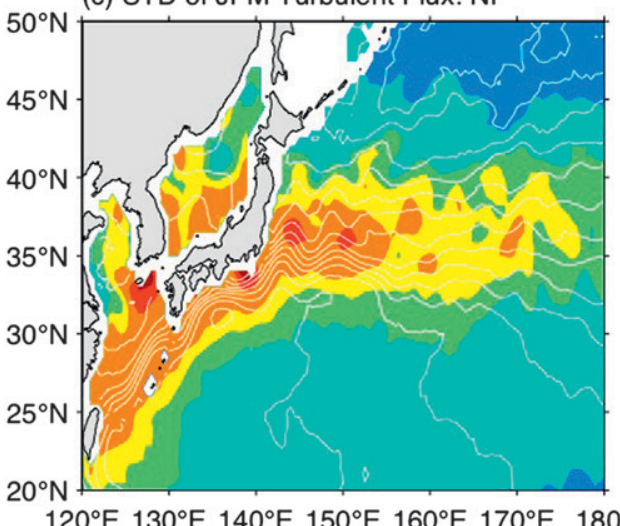

(d) Topography and Mean SSH: NA

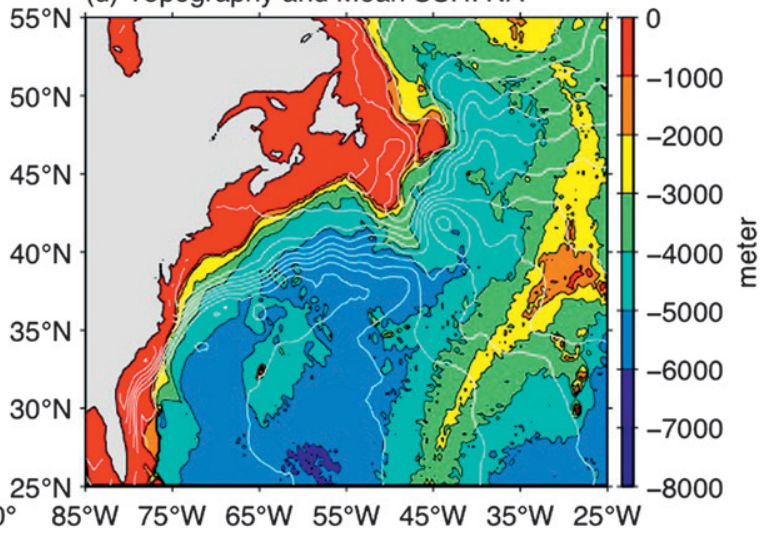

(e) RMS amplitude of SSH variability: NA

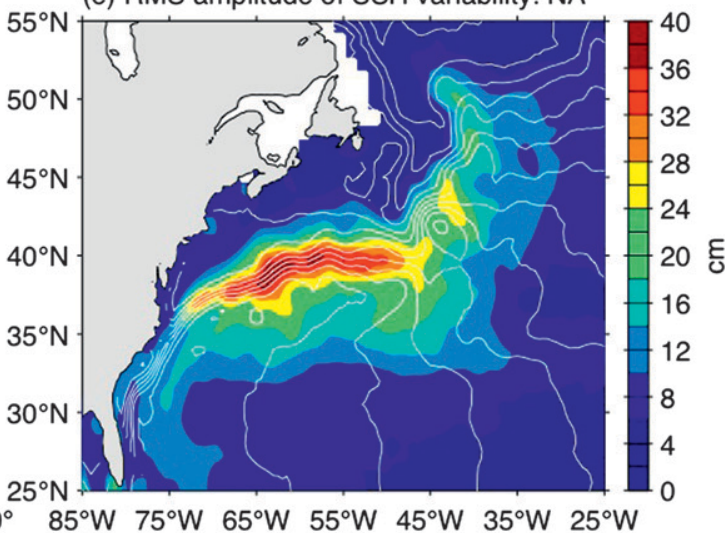

(f) STD of JFM Turbulent Flux: NA

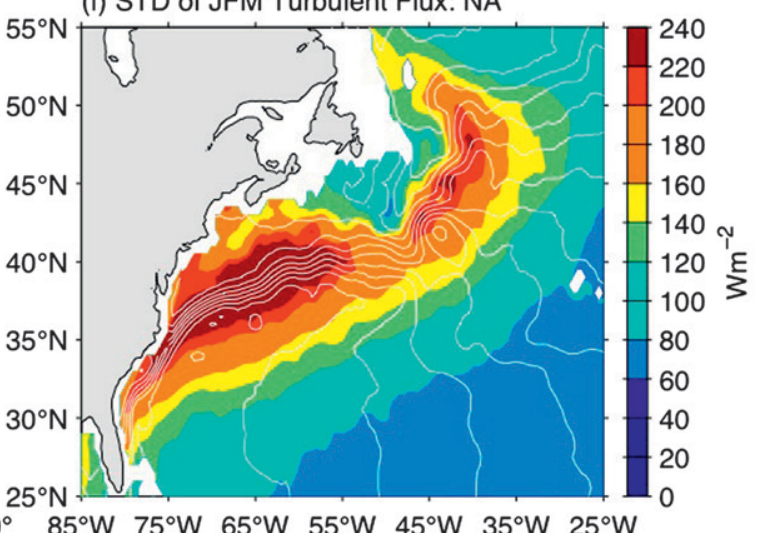

FIG. 1. Variability and topography of the western boundary currents. North Pacific (a) bottom topography, (b) standard deviation of weekly sea surface height, and (c) standard deviation of daily wintertime (January-March) turbulent heat flux. (d),(e),(f) As in (a),(b),(c), but for the North Atlantic. Mean dynamic height from Maximenko and Niiler (2004) overlaid in white on all panels.

in air-sea fluxes in the KE region are correlated with changes in the strength of heat advection with a lag of 1-2 yr, suggesting predictability in the transfer of heat to the atmosphere (Kwon and Deser 2007).

These two WBC systems have similar dynamical and thermodynamical roles in the ocean but may differ somewhat in their air-sea interactions. The GS and KE have different orientations, as well as different geography with respect to nearby land. The two WBCs are part of very different larger circulations: the GS is the warm northward branch of the Atlantic meridional overturning circulation (AMOC; Hurrell et al. 2003), which 
has a cold, deep return flow, the deep western boundary current (DWBC). In the North Pacific, there are two SST fronts (Yasuda 2003), of which the stronger North Pacific SST front corresponds to the Oyashio Extension and the combined system is referred to as the KuroshioOyashio Extension (KOE).

In this study we present parallel analyses of observations of the GS and the KE, as well as comparisons of previous separate studies. Our goal is to explore what is common to these WBCs and what is different, and to stimulate the formulation of hypotheses about the role of WBCs in atmosphere-ocean interaction and climate variability. Improved resolution in observations is available from satellite sensors, in particular, from the mapped fields of altimetric sea surface height (SSH) and sea surface temperature (SST). The relatively short satellite data records are supplemented by in situ observations to characterize the longer time scales and the representativeness of the satellite observation periods.

A companion paper presents theoretical and large-scale modeling studies of the WBCs, and investigates their relationship to atmospheric variability, along with climate implications (Kwon et al. 2010). More figures from this study (http://kkelly.apl.washington.edu/projects/wbcwg) and an interactive data archive for the large-scale analysis (http://www.cdc.noaa.gov/WBC) are provided to supplement the articles.

We start with a review of the current state of understanding of air-sea interaction over the WBCs in section 2 to motivate the importance of understanding the differences in the two WBC systems (section 3) and their contributions to air-sea interaction. We follow these descriptions with a comparison in section 4 of the dynamics and thermodynamics of the WBCs, followed by a discussion in section 5 of their implications for air-sea interaction and suggestions for further study. Major points are summarized in section 6 .

The authors of this paper are members of a working group on the western boundary current air-sea interaction (http://www.usclivar.org/Organization/wbc-wg.html), sponsored by the U.S. Climate Variability and Predictability (CLIVAR) Research Program. Some of the authors participated in field programs in the North Pacific [Kuroshio Extension System Study (KESS)/Kuroshio Extension Observatory (KEO); see information online at http://www. uskess.org] and in the North Atlantic [CLIVAR Mode Water Dynamic Experiment (CLIMODE); see information online at http://www.climode.org], which are producing detailed observations of the currents, water properties, and eddies, as well as the intense air-sea fluxes over the WBCs. Some preliminary results from these programs are presented here.

\section{Air-sea interaction and WBCs: A brief overview}

The WBCs are the sites of intense air-sea exchange in the Northern Hemisphere winter because cold, dry continental and subarctic air masses are carried eastward and offshore by the midlatitude westerlies, passing over the cold coastal ocean and then over the warm WBCs. The associated air-sea interaction processes include phenomena that cover a wide range of scales, from frontal effects associated with the mesoscale sea surface temperature gradients across the WBCs, to the ocean basin and even global scales associated with the midlatitude storm tracks. Note that the term "storm track" frequently refers to (Eulerian) regions of high wind variability at synoptic time scales (approximately 1-7 days) rather than to the actual (Lagrangian) paths of individual storms or their statistics.

\section{a. WBC temperature structure and air-sea fluxes}

The air-sea temperature differences and their impact on air-sea fluxes depend both on the ocean circulation and on the land-sea geometry. The warm water of the WBCs is rapidly advected northward into a region of much colder air temperatures, particularly in winter, resulting in large losses of heat to the atmosphere. The contrast between the warm core of the WBCs and adjacent waters gives rise to particularly large SST gradients: more than $10^{\circ} \mathrm{C}$ over just $200 \mathrm{~km}$ in the GS (Fig. 2, top panels) and an SST gradient that is nearly as large in the KE (Fig. 3, top panels). CLIMODE meteorological measurements show that the wintertime GS SST can exceed air temperature by as much as $15^{\circ} \mathrm{C}$ during a coldair outbreak (CAO; Fig. 4, middle panel). Comparisons of measurements from a ship repeatedly crossing the GS with those from a buoy that drifted with the current (Fig. 4, top panel) reveal that spatial variations in the air-sea temperature difference are nearly as large as the synoptic variations. Turbulent heat fluxes as large as $1000 \mathrm{~W} \mathrm{~m}^{-2}$ were measured over the GS using the direct covariance method during the CLIMODE field program in 2007 (The CLIMODE Group 2009), while mooring observations just north of the KE jet show mean values of more than $600 \mathrm{~W} \mathrm{~m}^{-2}$ during wintertime northerly wind events (Konda et al. 2010). The cold continental air that causes the CAO sweeps directly over the GS front, whereas the Siberian air masses first encounter the Japan/East Sea before heading out over the KE (Fig. 5). Despite this long path for continental air masses, the wintertime mean air-sea temperature difference over the KE is as large as that over the GS, suggesting that the Japan/East Sea does not appreciably warm the overlying air.

The effect of the WBCs on the latent and sensible fluxes can clearly be seen in high-resolution turbulent 

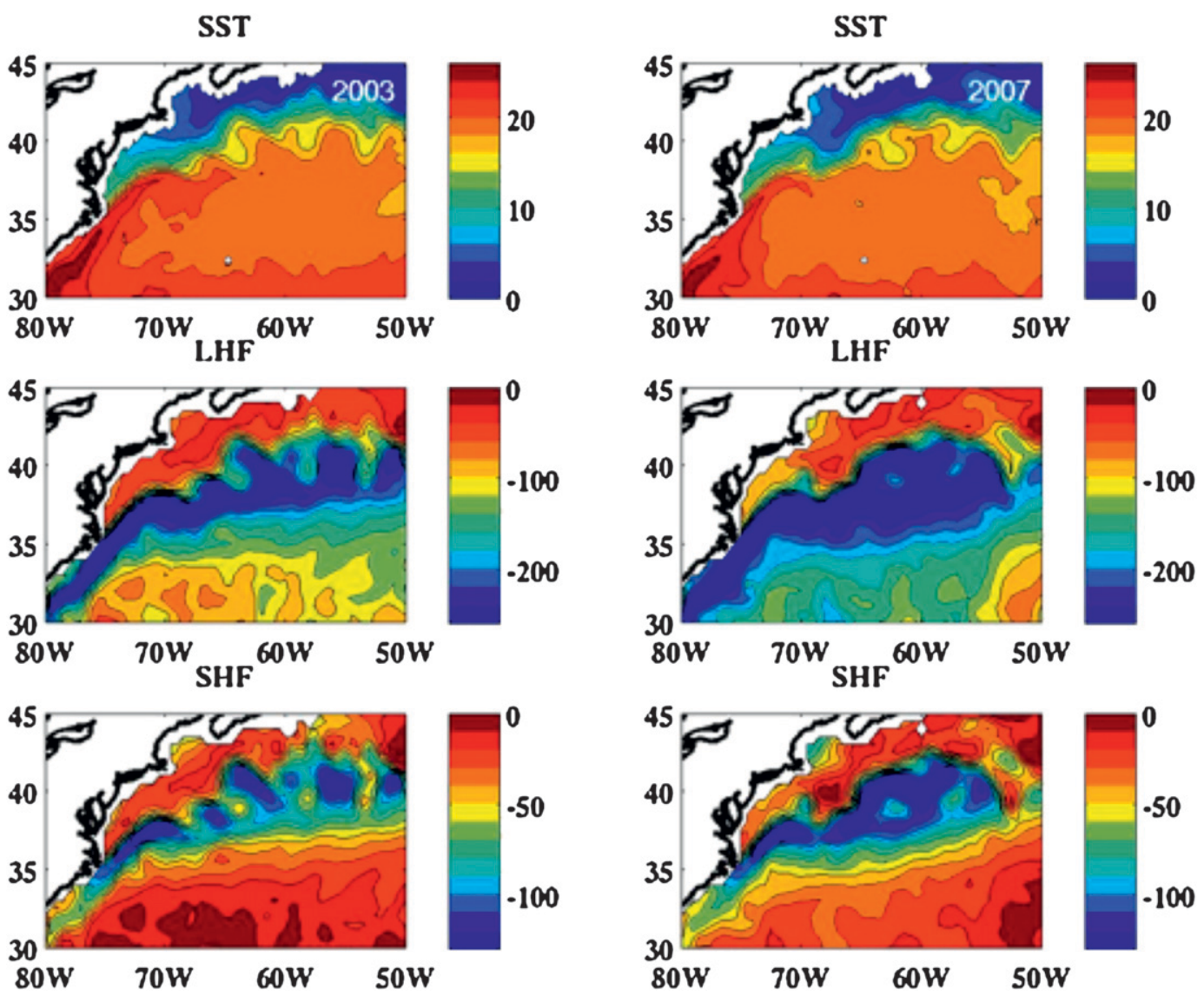

FIG. 2. Interannual variations in March SST and latent and sensible heat flux in the North Atlantic. (top) March averages of SST for (left) 2003 and (right) 2007. (middle) Latent and (bottom) sensible heat fluxes using the COARE bulk formula (Fairall et al. 1996). SST fields are from the Remote Sensing Systems on a $0.25^{\circ}$ grid. Inputs to the COARE algorithm were microwave SST, QuikSCAT winds, and ECMWF for other atmospheric variables.

heat flux fields ${ }^{1}$ (Figs. 2 and 3, middle and lower panels). In March, latent (sensible) heat fluxes exceed 200 (100) $\mathrm{W} \mathrm{m}^{-2}$ over the core of the WBCs. The standard deviation of the turbulent heat flux is much greater over the GS than over the KE (Figs. 1c,f), possibly owing to higher synoptic activity: the Eulerian storm-track statistics in the Pacific reach a maximum farther downstream from the western boundary than in the Atlantic (see, e.g., Hoskins and Hodges 2002, and references therein). The influence of the GS on the overlying

\footnotetext{
${ }^{1}$ Heat flux fields on a $0.5^{\circ}$ grid were produced using the Coupled Ocean-Atmosphere Response Experiment (COARE) bulk formula (Fairall et al. 1996) by combining microwave SST from Remote Sensing Systems with wind speed from Quick Scatterometer (QuikSCAT) and other atmospheric variables from the Tropical Ocean and Global Atmosphere (TOGA) Global Advanced Operational Surface Analysis, a high-resolution output from the European Centre for Medium-Range Weather Forecasts (ECMWF) operational mode with a resolution of about $1.125^{\circ}$.
}

atmosphere extends well into the ocean interior (Fig. 1f), where part of the GS flows into the North Atlantic Current (NAC). In contrast, the Kuroshio fluxes much of its heat to the atmosphere upstream of its separation from the Japan coast (Fig. 1c). Numerical weather prediction and climate models tend to underestimate the impact of the narrow WBCs on the fluxes, in part owing to the use of low-resolution SST products (Song et al. 2009).

\section{b. Boundary layer interactions and near-surface winds}

The study of air-sea interaction on the spatial scale of ocean fronts and eddies has been reviewed by Chelton et al. (2004), Xie (2004), and Small et al. (2008). Some of the main findings of these studies are that the surface stress, heat fluxes, and marine boundary layer structure are systematically modified across the WBCs, owing to changes in surface stability as air flows across the SST gradient. Instability over warm water leads to an increased vertical exchange of momentum, as well as to 

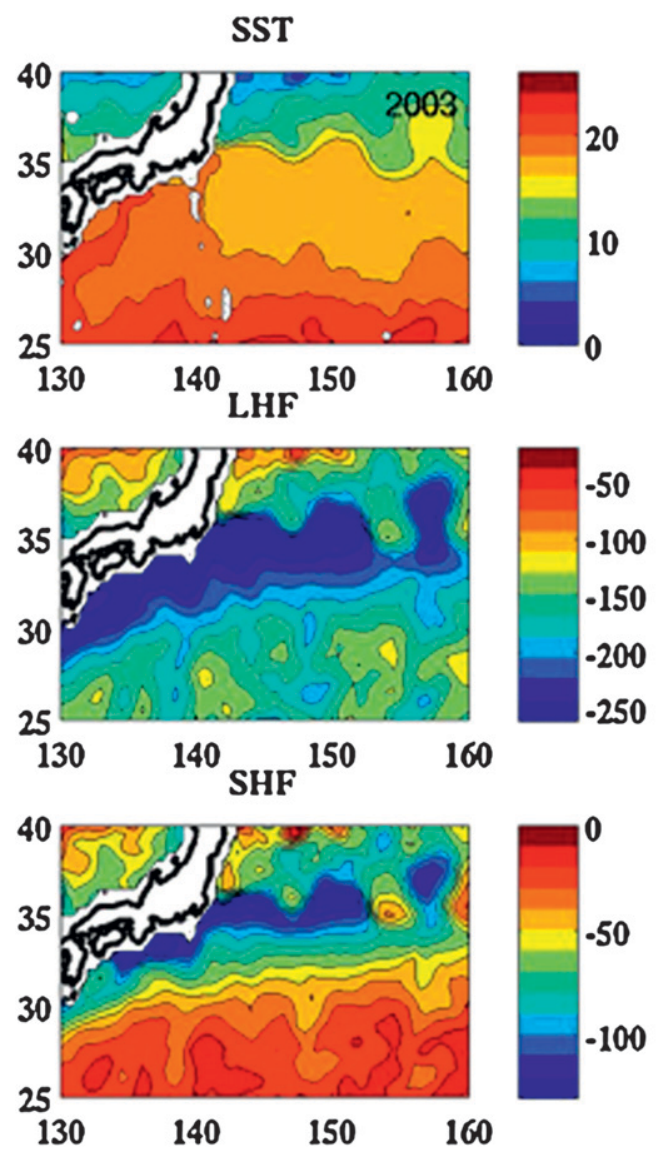
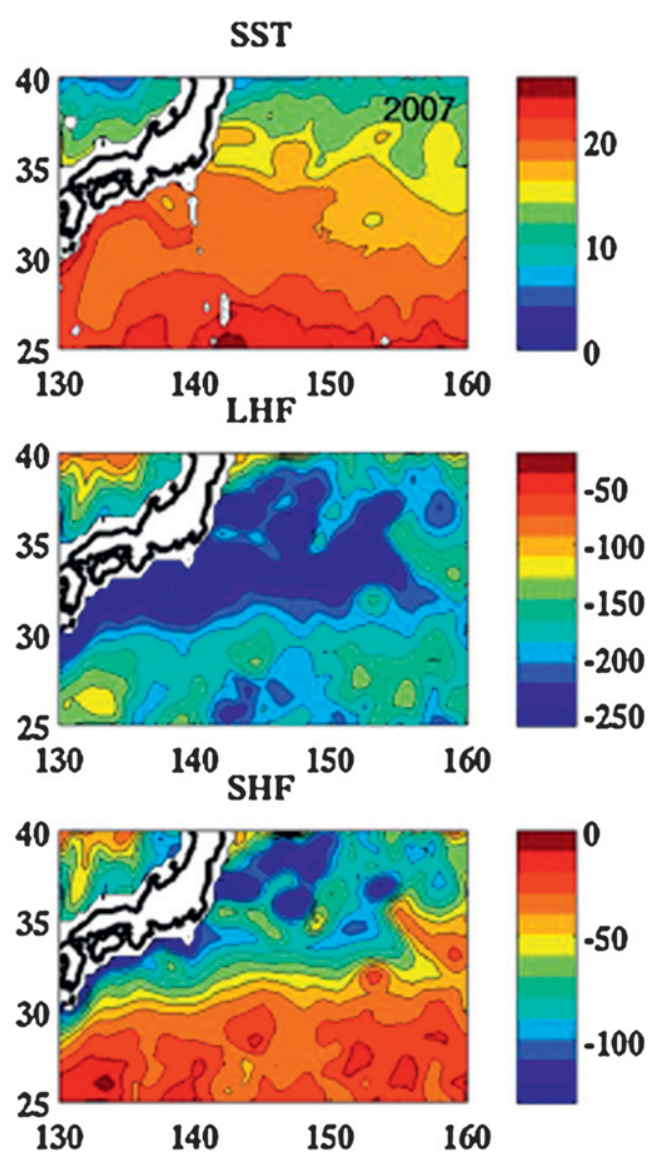

FIG. 3. As in Fig. 2, but in the North Pacific.

the establishment of winds driven by the changes in air density (akin to a sea breeze). These effects generally lead to stronger winds and larger heat fluxes from the ocean to the atmosphere over warm SST (Chelton et al. 2004; Xie 2004).

SST fronts such as the GS modify the shear in the lower-atmosphere wind profile (Sweet et al. 1981) and cause changes in boundary layer height of up to $2 \mathrm{~km}$, as was observed during a CLIMODE cruise (Fig. 6). This may be accompanied by changes in cloud height (Holt and Raman 1992) and formation of secondary circulations (Wai and Stage 1989). The effect of the ocean front on the atmospheric boundary layer can vary by season. For example, instability in wintertime northwesterly winds crossing the KE creates 2-km-high boundary layers over warm meanders and stable conditions over cold water (Tokinaga et al. 2006). In summer, warm advection from the subtropics across the KE can lead to fog formation over cold water, while cold advection from the north leads to a deepening of the atmospheric mixed layer and rising of the cloud base by over $200 \mathrm{~m}$ over warm water (Tanimoto et al. 2009). In CAOs over the North Atlantic, Young and Sikora (2003) noted that the location where cloud streets originate moves from the shelf in early winter to the GS north wall by spring as shelf waters cool. Changes in cloud cover over ocean features can provide either positive or negative feedback to SST: stratiform clouds that form over cold water should exert positive feedback (Norris and Leovy 1994), whereas convective clouds that form along the WBC axis should exert negative feedback [S. P. Xie 2009, personal communication; see also Deser et al. (1993) for a related situation over the warm phase of tropical instability waves].

High-resolution wind observations from satellite scatterometers have revealed the fine structure of the wind stress curl and divergence fields over WBCs that are linearly related to SST gradients seen in satellite microwave SST products (Chelton et al. 2004). In addition to the effect of SST gradients on stability of the marine boundary layer, the strong ocean currents can affect the wind stress (Cornillon and Park 2001; Kelly et al. 2001) because stress depends on the relative motion of the atmosphere and the ocean.

The relationship between ocean fronts and the surface expression of the atmospheric midlatitude storm tracks has been explored by Sampe and Xie (2007) and Booth 

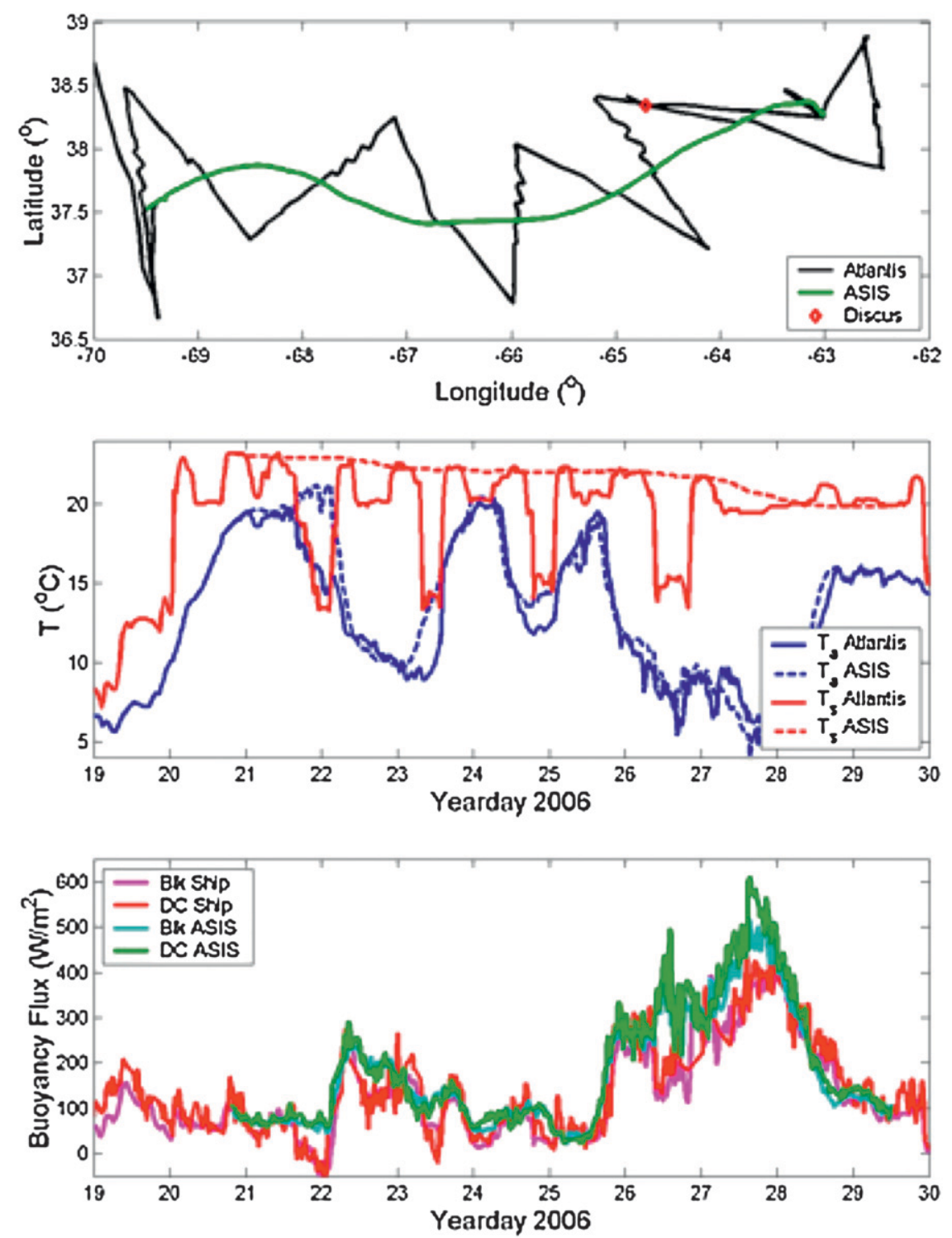

FIG. 4. Air-sea fluxes during the CLIMODE cruise. (top) Relative locations of the three platforms used to estimate surface fluxes during the 2006 field program: the Research Vessel (R/V) Atlantis, a drifting Air-Sea Interaction Spar (ASIS) buoy, and a moored (discus) buoy. (middle) Time series of air and sea surface temperature from the ship and ASIS during the transects shown in the top panel. (bottom) Direct covariance and bulk estimates of the buoyancy fluxes. From The CLIMODE Group (2009).

et al. (2010). Whereas the large-scale envelope of the strong wind occurrence corresponded closely to the classic free-tropospheric storm tracks (Chang et al. 2002; Hoskins and Hodges 2002), local modulations occurred on the scale of the WBCs. For instance, strong winds in winter tend to occur more frequently over the warm core of the GS and in the relatively warm water in the NAC (Fig. 7; near $50^{\circ} \mathrm{N}, 40^{\circ} \mathrm{W}$ ), where air-sea temperature differences create an unstable boundary layer.

\section{c. Cyclogenesis and synoptic development}

Several researchers have suggested that individual synoptic weather systems are modified and often enhanced when they pass over the strong SST gradients of the WBCs (Sanders and Gyakum 1980; Sanders 1986; Cione et al. 1993). A Lagrangian study by Hoskins and Hodges (2002) shows large growth rates and genesis densities over the GS and to the east of Japan over the KE (Fig. 8). Rapidly 

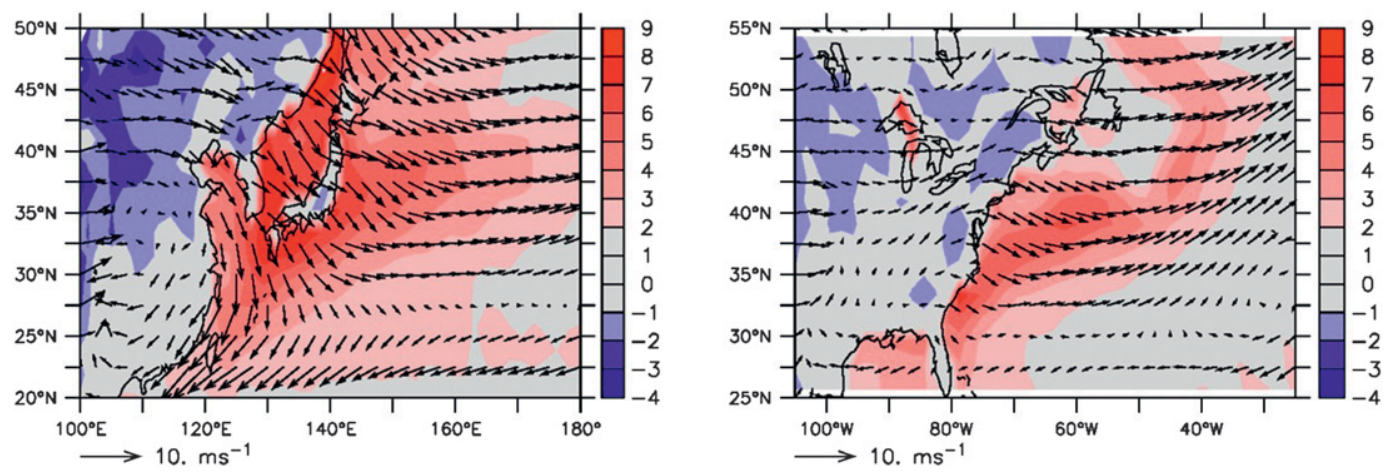

FIG. 5. Climatological mean November-March surface wind overlaid on surface skin minus air temperature in the (left) KE and (right) GS regions. Climatological fields are from the NCEP-National Center for Atmospheric Research (NCAR) reanalysis (Kalnay et al. 1996). Temperature differences are in degrees Celsius.

growing synoptic storms ("bombs") can intensify over, and track along, both the GS and the KE (Colucci 1976; Sanders and Gyakum 1980; Businger et al. 2005; Chen et al. 1992; Yoshida and Asuma 2004). Many authors have noted that the enhancement of low-level baroclinicity by SST gradients will likely increase synoptic storm activity (Nakamura and Shimpo 2004). The baroclinicity is proportional to the horizontal air temperature gradient divided by the buoyancy frequency $N$ (Nakamura et al. 2004), which by thermal wind is proportional to the vertical shear of the horizontal wind multiplied by $f / N$ (where $f$ is the Coriolis force). Indeed, Cione et al. (1993) used the horizontal thermal gradient between the air temperature at Cape Hatteras and SST at the GS north wall as a measure of baroclinicity with which to estimate the potential growth of storms passing that way. Nakamura and Shimpo
(2004) found that within the core region of the Southern Hemisphere storm track and subpolar jet over the Indian Ocean, the lower-troposphere eddy activity was strongly influenced by the baroclinicity in the atmospheric boundary layer, which is, in turn, closely related to the SST gradient. The relationship between storm tracks and ocean fronts in all ocean basins has been reviewed by Nakamura et al. (2004).

In addition to the influence on baroclinicity, ocean fronts affect the diabatic heating of the atmosphere through surface fluxes. Differential diabatic heating at the surface can act to either enhance or reduce the low-level thermal structure, that is, atmospheric fronts (Doyle and Warner 1990; Giordani and Caniaux 2001; Persson et al. 2008), and can be very important in the growth stage of storms (Kuo et al. 1991). Latent heating in the troposphere was found

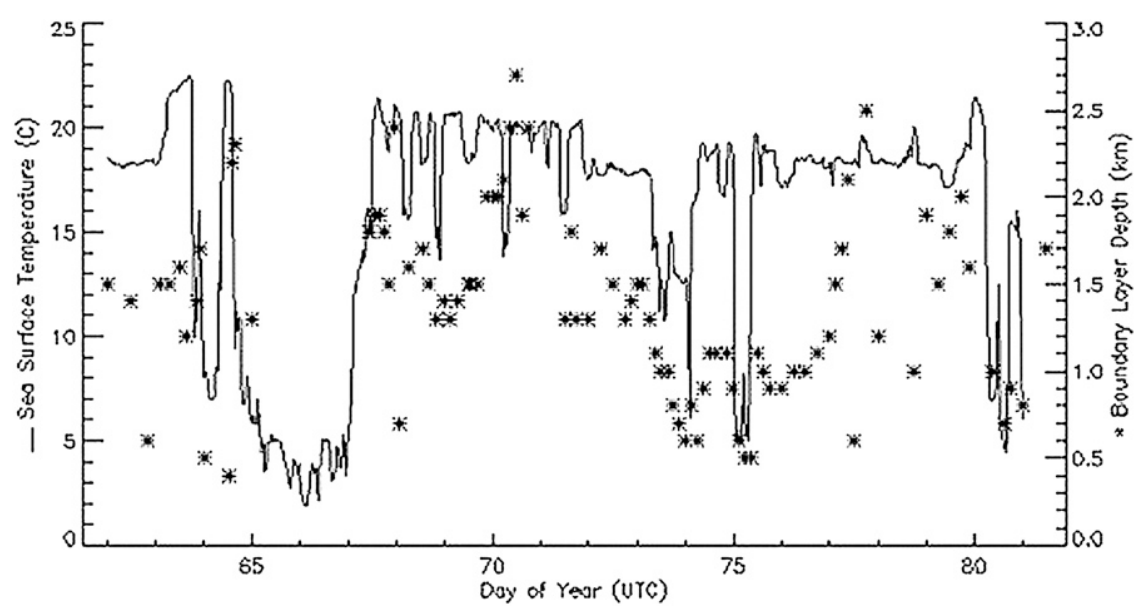

FIG. 6. Atmospheric boundary layer depth over the GS region during a CLIMODE cruise on R/V Knorr, 2-22 Mar 2007. Along-track SST (solid line) and marine atmospheric boundary layer depth (*). The cruise track begins at Bermuda, heads northward to Cape Cod (the lowest SST is at day 67 ), and then backtracks to follow the GS from about $70^{\circ}$ to $50^{\circ} \mathrm{W}$ and back. Boundary layer height was estimated from radiosonde soundings and wind profiler reflectivity (Brown and Edson 2009). 


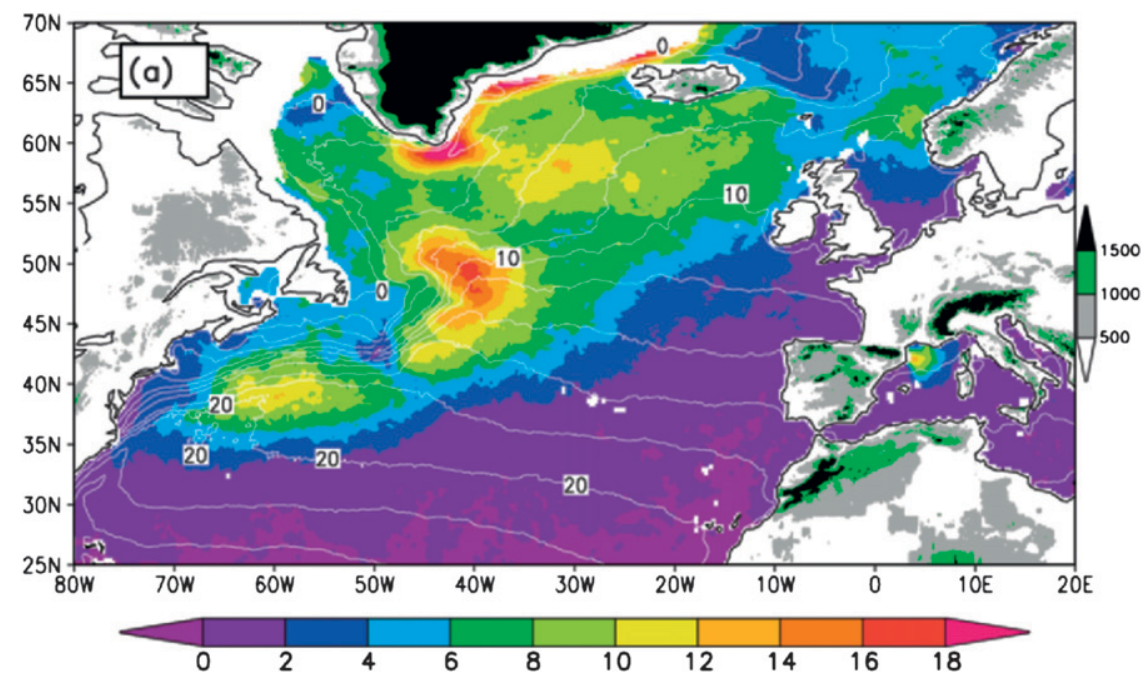

FIG. 7. Winter [December-February (DJF)] climatology of the frequency of high wind events $\left(>20 \mathrm{~m} \mathrm{~s}^{-1}\right.$ ) from QuikSCAT (color, \%) and Advanced Very High Resolution Radiometer (AVHRR) climatological mean SST (white contours at an interval of $2^{\circ} \mathrm{C}$ ). Topography higher than 500-, 1000-, and 1500-m altitudes is shaded (see color bar). From Sampe and Xie (2007; reproduced by permission of the American Meteorological Society).

by Stoelinga $(1996)$ to cause a low-level $(\approx 800 \mathrm{mb})$ potential vorticity (PV) anomaly. More recently, diabatic heating was found to induce an upper-level mass flux divergence to enhance a storm and also destabilize the atmosphere (Businger et al. 2005).

Although atmospheric eddy heat fluxes will act to reduce the sharp meridional air temperature gradients (e.g., Holton 2004), the WBC SST front, which is maintained by advection and subsurface heat storage, can restore the air temperature gradient. Hoskins and Valdes (1990) used reanalysis data to show that the diabatic heating in the lower and midtroposphere, which occurs as synoptic storms pass across the land-sea boundary and then over the WBCs, acts to sustain the baroclinicity. They hypothesized that as the storm-track winds help drive the WBCs, this forms a self-maintaining (coupled) system. An alternative mechanism recently proposed by Nakamura et al. (2008) is that airflow across sharp SST gradients sets up differential surface sensible heat fluxes, which act to maintain the near-surface baroclinicity against eroding eddy heat fluxes, a mechanism that is dubbed the “oceanic baroclinic adjustment." Using a high-resolution
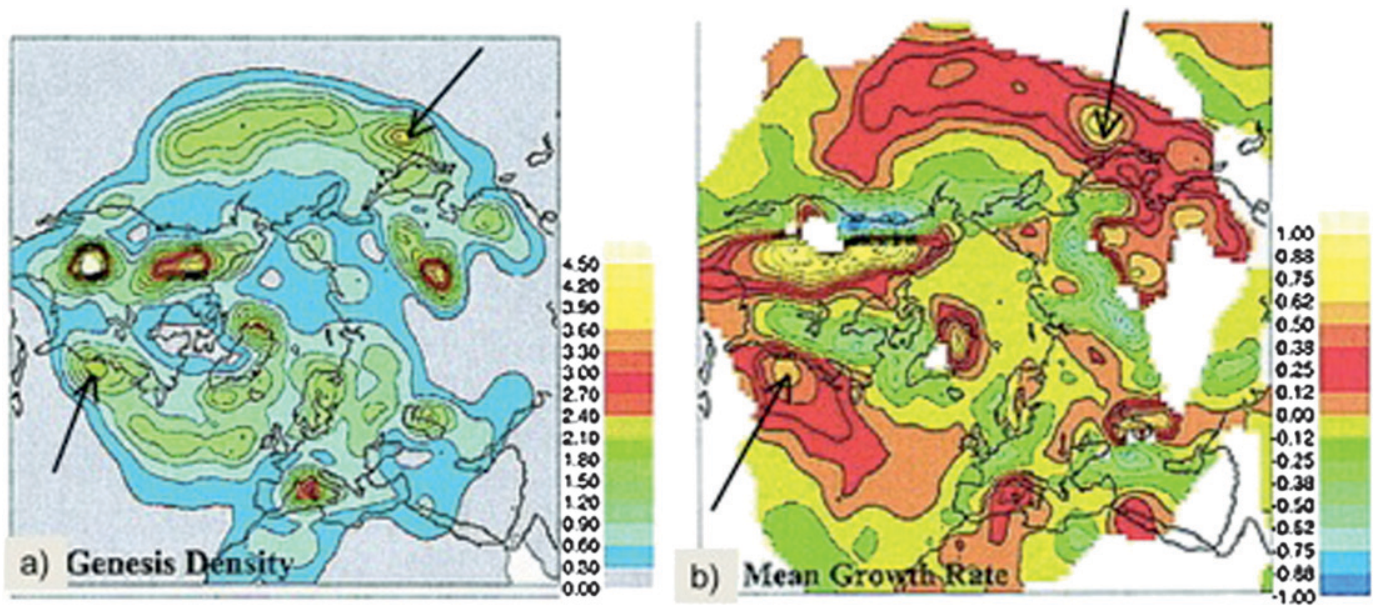

FIG. 8. Lagrangian storm-track characteristics, obtained from tracking of positive relative vorticity features at $850 \mathrm{hPa}$. (a) Genesis density and (b) mean growth rate $\left(\right.$ day $\left.^{-1}\right)$. Arrows point to high growth rate and genesis regions located close to the Gulf Stream and Kuroshio Extension regions. Modified from Hoskins and Hodges (2002). 


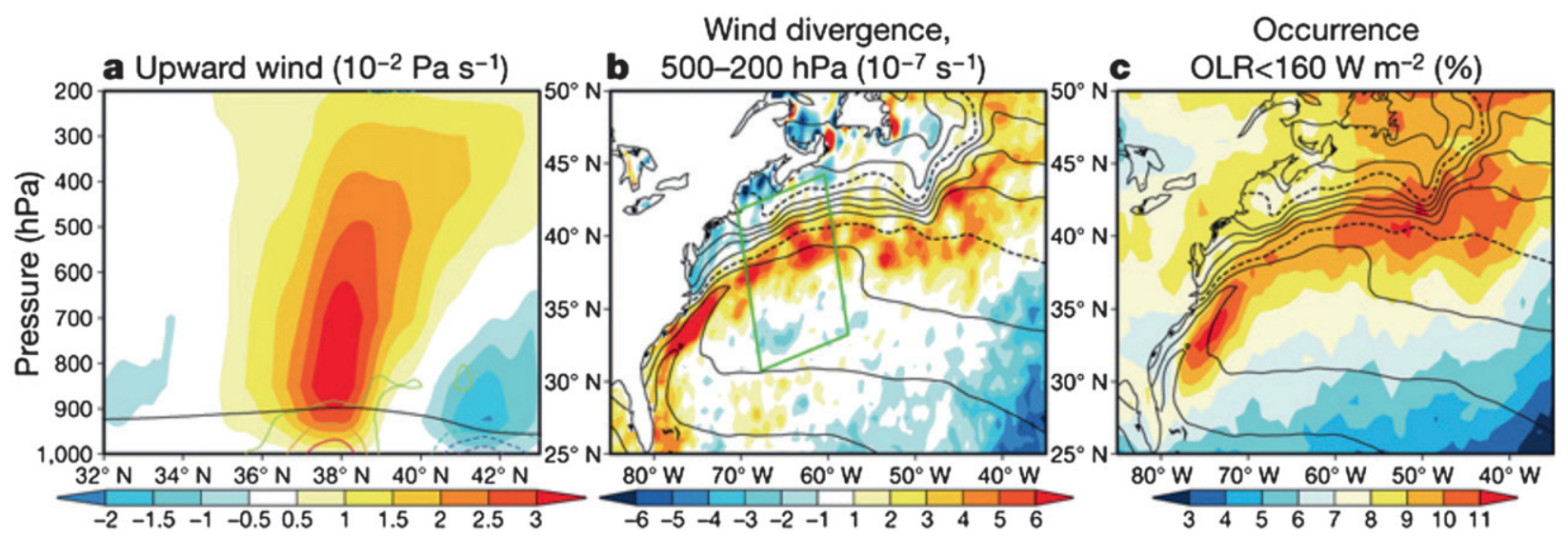

FIG. 9. Annual climatology of parameters connecting MABL and free atmosphere. (a) Vertical wind velocity (upward positive; color), boundary layer height (black curve), and wind convergence (contours for $\pm 1,2,3 \times 10^{-6} \mathrm{~s}^{-1}$ ) averaged in the alongfront direction in the green box in (b) based on the ECMWF analysis. (b) Upper-tropospheric wind divergence averaged between 200 and $500 \mathrm{hPa}$ (color). (c) Occurrence frequency of daytime satellite-derived OLR levels lower than $160 \mathrm{~W} \mathrm{~m}^{-2}$ (color). SST contours (black) in (b) and (c) with interval of $2^{\circ} \mathrm{C}$ and dashed contours for $20^{\circ}$ and $10^{\circ} \mathrm{C}$. Reproduced from Minobe et al. (2008).

atmospheric regional model of the Asian/Pacific domain, Taguchi et al. (2009) note that the mean and variance of the sensible heat flux, as well as the storm-track activity, are much reduced when the KE SST front is smoothed out.

\section{d. Deep atmospheric response to WBCs}

A deep-tropospheric response to ocean fronts has been shown recently by Liu et al. (2007) for the Agulhas Return Current, by Tokinaga et al. (2009a,b) for the KE, by Kobashi et al. (2008) for the North Pacific subtropical front, and by Minobe et al. (2008) for the GS. For example, Minobe et al. (2008) found a measurable vertical velocity to heights of $300 \mathrm{hPa}$, together with an uppertropospheric horizontal divergence signal directly over the GS, which they have argued is a direct response to SST-driven boundary layer interactions at the GS front (Fig. 9). Minobe et al. (2008) suggest that deep convection is occurring over the GS and that planetary waves may consequently be excited by the deep heating, with far-field effects extending to Europe. An alternative interpretation is that the vertical velocities may be related to the enhanced baroclinic development over the GS; in this case, the dominant effect may be on the storm track itself, rather than exciting quasi-linear planetary wave propagation.

\section{Oceanography of the GS and KE systems}

To understand the complex air-sea interactions in the WBCs, knowledge of regional ocean dynamics and thermodynamics is necessary. The large contribution of oceanic heat advection in the WBC regions makes the air-sea interaction markedly different from that of the open ocean, where ocean temperature anomalies are forced primarily by air-sea fluxes (Cayan 1992; Barsugli and Battisti 1998). The importance of advection can be inferred directly from the large annual average of net surface heat flux, which exceeds $100 \mathrm{~W} \mathrm{~m}^{-2}$ in the WBC regions; this heat is supplied by a mean heat convergence from the WBCs for which velocities can exceed $2 \mathrm{~m} \mathrm{~s}^{-1}$. Anomalies in the rate of convergence are associated with changes in the currents and contribute to anomalies in the air-sea heat exchange.

Along the southern edge of these WBCs, ocean stratification reaches a minimum in the thick isothermal layer of the subtropical mode water (STMW; Worthington 1976; Hanawa and Talley 2001). Large quantities of heat in can be stored in this thick layer with just a small change in temperature or stratification. The large heat storage anomalies can contribute to climate memory. A primary goal for both KESS and CLIMODE is to understand the formation and dissipation of STMW.

\section{a. Mean WBC properties}

The standard deviation of SSH tracks the region of strong meanders of the boundary currents (Figs. 1b,e), which is nearly zonal for the KE but trends northeastward with downstream distance for the GS. Both WBCs traverse relatively steep topography (Figs. 1a,d), which likely influences the mean path: the Ogasawara-Izu Ridge at $140^{\circ} \mathrm{E}$ and the Shatsky Rise at $160^{\circ} \mathrm{E}$ in the Pacific and the New England seamounts at $58^{\circ}-63^{\circ} \mathrm{W}$ in the Atlantic. A modeling study by Ezer (1994) suggests that the New England seamounts force a stabilization of the mean path. 
In addition, the Mid-Atlantic Ridge appears to confine high SSH variability to the western part of the basin. For the western North Pacific, the presence of the Shatsky Rise has been found numerically to be responsible for generating the two quasistationary meanders in the KE path with peaks at approximately $143^{\circ}$ and $150^{\circ} \mathrm{E}$ (Fig. 1b; Hurlburt and Metzger 1998).

Both WBCs are accompanied by recirculation gyres. The southern recirculation gyre (SRG) has a larger longitudinal extent in the Atlantic, approximately $20^{\circ}$ versus $10^{\circ}$ in the Pacific, as suggested by the mean dynamic topography (white contours in Figs. 1a,d). North of the eastward-flowing current core, the GS has a robust northern recirculation gyre (NRG) and slope current (Hogg et al. 1986). In contrast, the Pacific NRG is weak in the surface dynamic height field, although it could be observed in the recent KESS profiling float, moored current meter, and pressure sensor-equipped inverted echo sounder (PIES) measurements (Qiu et al. 2008; Jayne et al. 2009).

The narrow warm core of the GS is more apparent in high-resolution SST products than it is the KE core (Figs. 2 and 3, top panels): it usually has a distinct southern boundary as far east as $60^{\circ} \mathrm{W}$. In contrast, the $\mathrm{KE}$ is actually an SST front after separation from Japan, with a distinct southern boundary only in the Kuroshio upstream of the separation point. This difference suggests that the warm core (and advection) plays a larger role for the separated GS than for the KE. Further, the existence of two separate SST fronts in the Pacific diffuses the effect of the warm water on the cold continental air passing over the region.

\section{b. Path and transport statistics}

The altimetric record clearly reveals that the WBCs vary temporally in strength, the latitude of the current axis, the amount of meandering, and the structure of the adjacent recirculation gyres. Here, we present indices that describe the temporal variations of the first three of these characteristics, which are based primarily on SSH. The structure of the SRGs appears to be related to the volume of STMW and this relationship is explored in subsequent sections.

Monthly paths from altimetric SSH reveal substantial interannual variations (Figs. 10 and 11); these paths were derived here using the maximum gradient of SSH at each longitude, thus neglecting the multiple paths arising from steep meanders. In contrast, Qiu and Chen (2006) use a constant SSH contour, which more clearly delineates the steep meanders.

An alternative index is the surface transport or SSH difference across the WBC. The path and the strength of the WBC were estimated simultaneously here by fitting an error function to meridional SSH profiles at each time and longitudinal grid point over a latitude interval of $4^{\circ}-6^{\circ}$ (Kelly and Gille 1990) centered on the WBC core. Transport estimated in this way is a Lagrangian measure of strength independent of path, and includes the eastwardflowing limbs of both the NRG and SRG. To obtain robust indices, paths and transports from the altimeter were zonally averaged over $52^{\circ}-72^{\circ} \mathrm{W}$ for the GS and over $140^{\circ}-160^{\circ} \mathrm{E}$ for the KE.

These indices exhibit substantial differences between the GS and KE (Fig. 12). In the KE both the path and transport indices (Figs. 12c,d) contain large low-frequency (decadal) changes, whereas interannual variability dominates in the GS (Figs. 12a,b). The standard deviation of path latitude for the KE is nearly twice as large as for the GS $\left(0.26^{\circ}\right.$ versus $\left.0.46^{\circ}\right)$. SSH in the SRG is the dominant contributor to surface transport anomalies in both the WBCs; however, the GS NRG makes a larger contribution than does the KE NRG. Although a more northerly path of the WBCs corresponds to a stronger jet, correlations using monthly values over $15 \mathrm{yr}$ are not significant at $95 \%$ confidence in the GS. The correlation of KE path and transport is only marginally significant at $95 \%$ because the dominant low frequencies of the variability increase the significance threshold.

GS (KE) path indices were also derived from the location of the $15^{\circ} \mathrm{C}\left(14^{\circ} \mathrm{C}\right)$ isotherm at 200-m depth (T200) in hydrographic data (Joyce et al. 2009; Fig. 13). The GS path index from the altimeter (dashed line) is significantly correlated $(\rho=0.58)$ with the hydrographic path (Fig. $13 \mathrm{~b}$, bold line). Using the longer hydrographic index, changes in the GS path have been shown to be lag correlated to the NAO (shading), suggesting a response to wind forcing (Joyce et al. 2000). The altimeter path index (dashed line) and T200 (bold line) are also positively correlated for the KE $(\rho=0.52)$, but not significantly (Fig. 13a). The longer record of the SST index (thin line) of Qiu et al. (2007) is significantly correlated with T200 $(\rho=0.40$ at zero lag and $\rho=0.47$ when SST leads by 6 months). The KE SST index closely resembles the PDO, which is not surprising because the PDO is derived from SST in the North Pacific. The T200 index is significantly (negatively) correlated with another atmospheric index, the North Pacific Index (NPI), with a lag of about 4 yr.

Recent work by Qiu and Chen (2005) suggests that another important descriptor of the ocean state is the amount of meandering or degree of "stability" of the path, as quantified by the length of the path over a fixed longitude range (Cornillon 1986). Qiu and Chen (2005) showed that the KE alternates between a "stable" (a short path with less meandering) and an "unstable" state. A stable state corresponds to a stronger SRG in the $\mathrm{KE}$ and a larger volume of STMW in the region, 

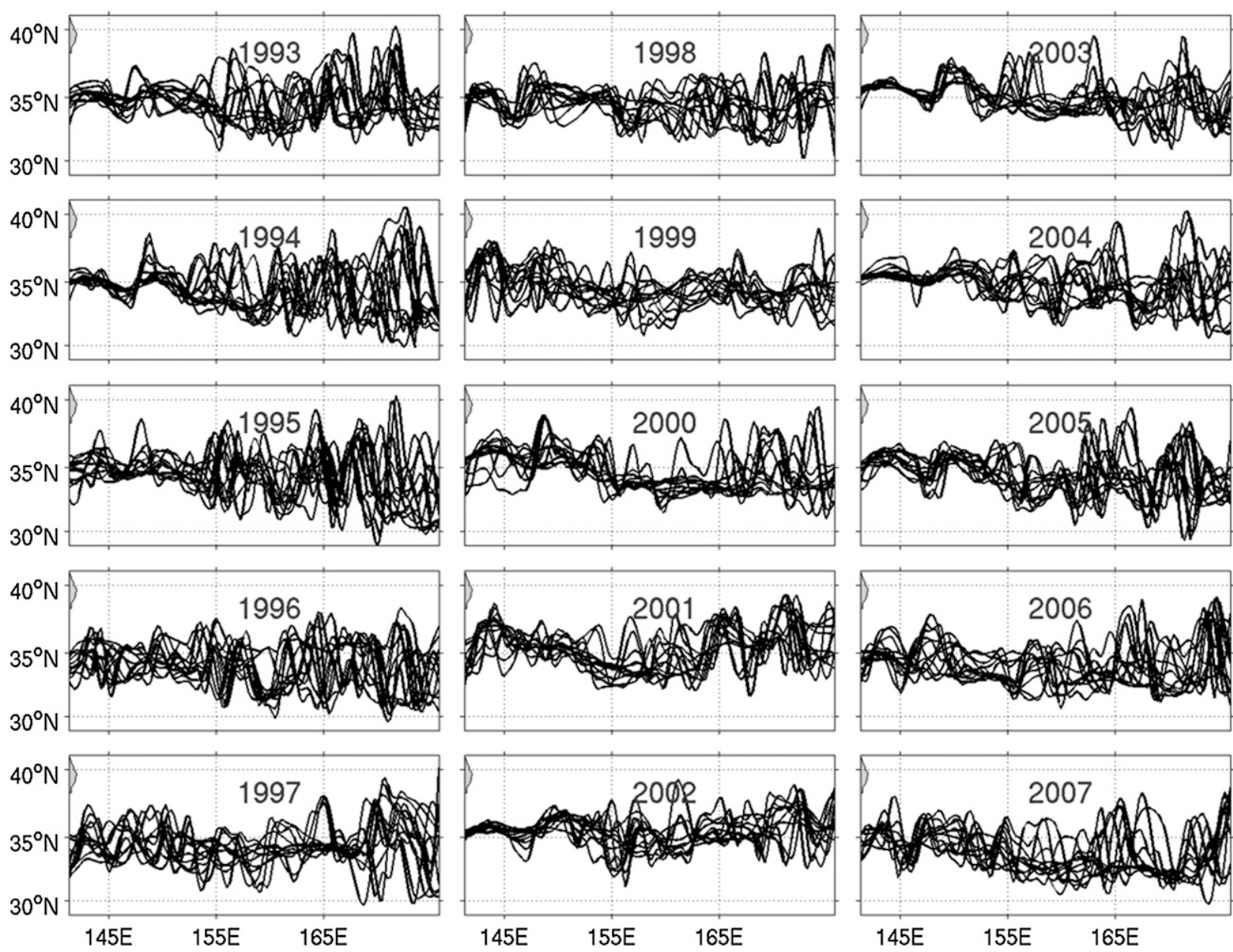

FIG. 10. Monthly paths of the Kuroshio Extension derived from altimetric sea surface height. The path was defined at each time and longitude as the location of the maximum meridional gradient of SSH.

whereas an unstable state is associated with substantial mixing across the WBC, as discussed in section $4 \mathrm{c}$.

Kelly et al. (2007) found a robust inverse correlation between the amount of meandering (instability) and the surface transport in the KE. The amount of meandering in that study and here was quantified as the standard deviation of path latitude over a 3-month period. Path instability (dashed line in Fig. 14) and transport (solid line) show the same robust anticorrelation in the GS as in the KE: larger surface transport corresponds to more stable paths. These results suggest that path stability and transport are important linked indices of the ocean state.

Between $74^{\circ}$ and $60^{\circ} \mathrm{W}$, the GS path location has been shown to be well correlated with surface velocity and deeper hydrographic variability in the slope water, found immediately to the north of the GS (Peña-Molino and Joyce 2008; Dong and Kelly 2003). Increased southwesterly flow in the SW was found to lead southward anomalies of the GS path (Fig. 15) by several months and associated lower SSTs north of the GS; these anomalies are, in turn, related to changes in the strength of the DWBC and the NRG (Peña-Molino and Joyce 2008). These changes relate the subsurface index of temperature at $400-\mathrm{m}$ depth to the fingerprint of the variable AMOC (Zhang 2008).

\section{c. SST signatures of path and transport anomalies}

Both the path and the transport anomalies described in the previous section are associated with changes in the SST. To estimate the SST anomalies for typical path and transport anomalies, each index was normalized by its standard deviation (one standard deviation of path anomaly is twice as large in degrees latitude in the KE as in the GS). Using the optimum interpolated SST (OISST) with infrared-only data on a $0.25^{\circ}$ grid (Reynolds et al. 2007) for 1993-2008, we first removed the seasonal cycle (once-per-year annual harmonic); then, at each grid point, we performed a regression of nonseasonal SST 

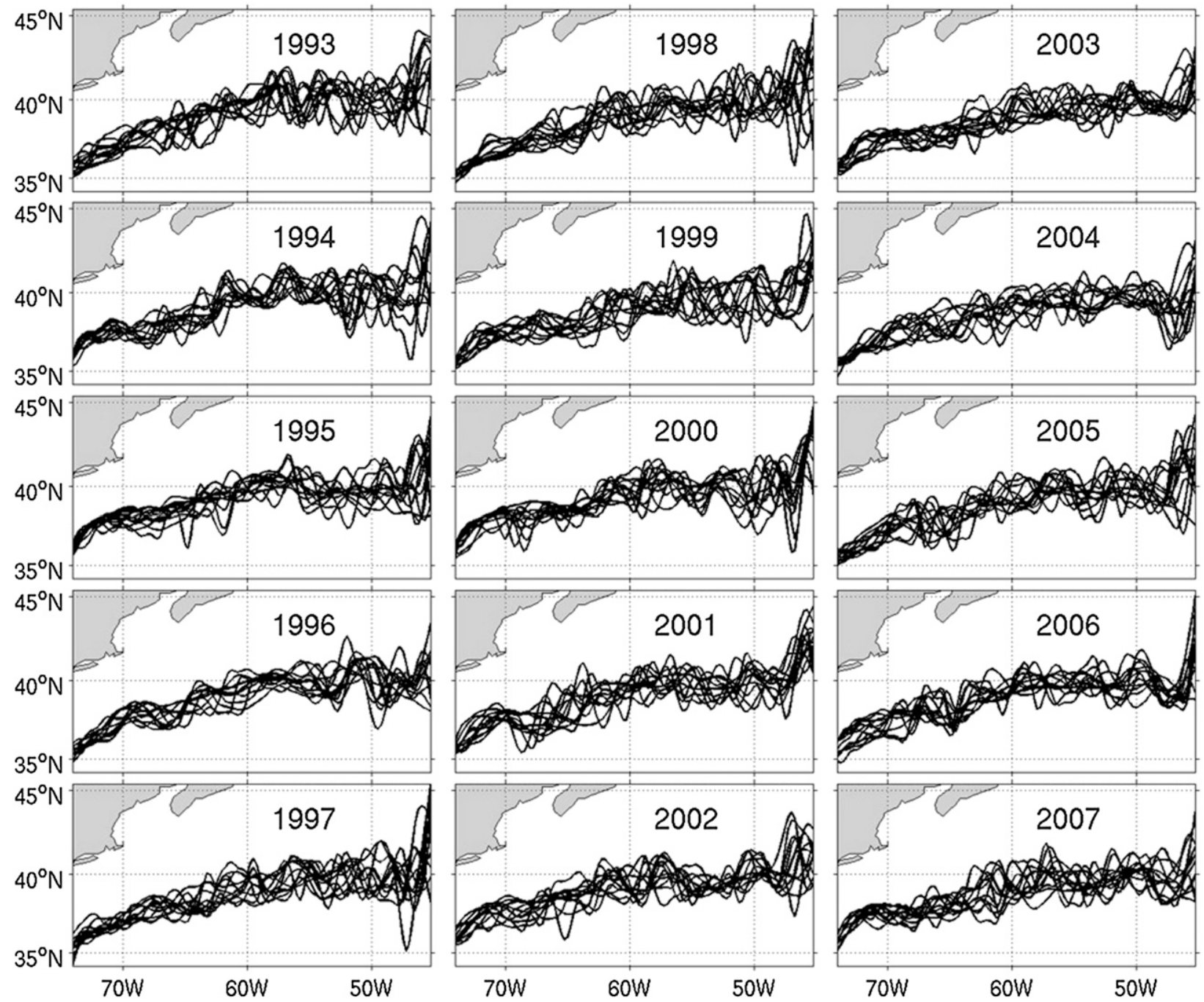

FIG. 11. As in Fig. 10, but for the Gulf Stream.

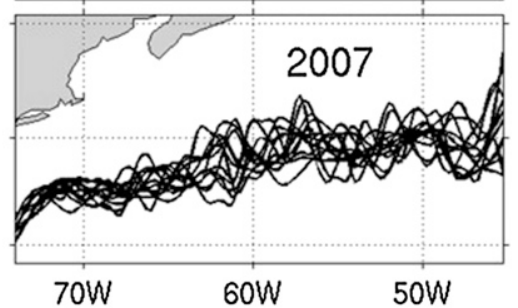

against each normalized index (none of which contains a significant seasonal cycle). The regression coefficients for those regions where the correlation exceeds the $95 \%$ significance level of $0.23(0.31)$ for the GS (KE) are enclosed by the bold contours in Fig. 16.

The results are similar, but differ in detail, for the two oceans. In both the GS and in the KE, a northward path anomaly (of one standard deviation) corresponds to a positive SST anomaly (up to $0.4^{\circ} \mathrm{C}$ ) near the mean axis (Figs. 16a,c); the GS also has lower SST to the south that is associated with the cooler water south of the current core (Fig. 2, top panels). In the KE there are positive anomalies throughout the eastern part of the study region, a signature that suggests that path changes correspond to largescale changes in North Pacific circulation [see section $4 \mathrm{~b}$ and Kwon et al. (2010)]. The SST signature of an increase in surface transport is a negative anomaly north of the current core (Figs. 16b,d). In the GS this SST anomaly is likely the result of the westward-flowing inshore branch of the NRG that advects cold water into the region (PeñaMolino and Joyce 2008). In the KE the negative SST anomaly $\left(-0.4^{\circ} \mathrm{C}\right)$ is concentrated in the western part of the domain and is accompanied by a positive SST anomaly along the current core and to the northeast.

\section{Thermodynamics and dynamics of the WBCs}

Analyses of the GS and the KE using SSH have revealed new aspects of these current systems, including the importance of heat storage and transport in the upperocean heat budget, mechanisms for STMW variability, and the relationship between the WBCs and wind forcing.

\section{a. Upper-ocean heat budget}

Climate models frequently use SST anomalies to represent the oceanic influence because air-sea fluxes are 

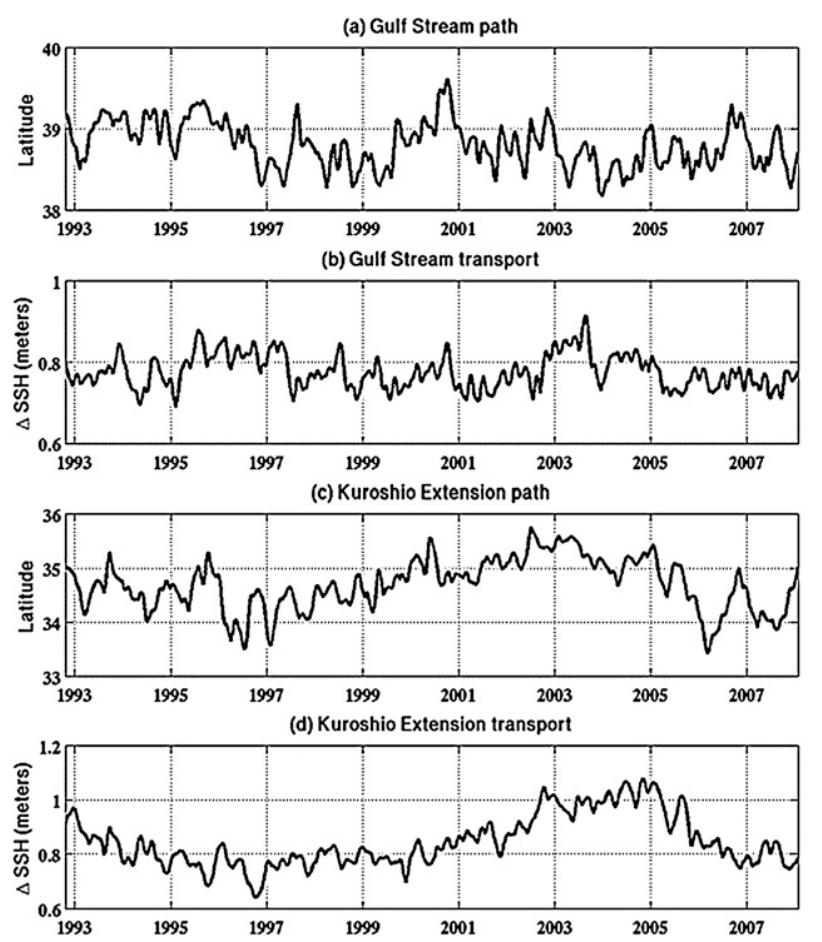

FIG. 12. Indices in the Gulf Stream and Kuroshio Extension regions. Zonally averaged index of (a) GS path latitude, (b) GS surface transport for $72^{\circ}-52^{\circ} \mathrm{W}$, (c) KE path latitude, and (d) KE surface transport for $140^{\circ}-160^{\circ} \mathrm{E}$.

a strong function of the instantaneous air-sea temperature difference. However, it has been argued that SST is more a consequence of air-sea interaction than of ocean dynamics (Sutton and Mathieu 2002), and neither SST nor air temperature in the marine boundary layer is representative of ocean or atmospheric states, respectively. Further, it has been demonstrated that ocean heat content is a better climate predictor than SST, because SST anomalies decorrelate rapidly on seasonal time scales (Deser et al. 2003). Oceanographers have implicitly recognized the importance of heat content by comparing wintertime SST anomalies, when the upper-ocean mixed layer is deepest and therefore most representative of the upper-ocean heat content. Heat content affects SST through entrainment of subsurface waters into the mixed layer [dubbed "re-emergence" by Alexander and Deser (1995)]. Thus, to examine the contribution of WBCs to air-sea fluxes on climate time scales it is necessary to understand the upper-ocean heat budget.

Analyses of the upper-ocean heat budget show that while air-sea fluxes dominate on seasonal time scales, the ocean contribution becomes increasingly important on longer time scales (Qiu and Kelly 1993; Kelly and Qiu 1995). In parallel studies of the KE and the GS in the upper $800 \mathrm{~m}$ (Vivier et al. 2002; Dong and Kelly 2004), the advection-plus-diffusion term was shown to be more highly correlated with interannual changes in heat storage rate than was surface heating, a result that is somewhat more compelling in the GS than in the KE (Fig. 17). In the Dong and Kelly (2004) study, where advection was explicitly decomposed into the contributions from geostrophic and Ekman currents, the geostrophic contribution was shown to dominate. Similarly, Qiu (2000) and Xie et al. (2001) showed that the largest contributor to interannual SST changes in the KE region is geostrophic advection, rather than air-sea fluxes or Ekman advection, which are frequently cited as important contributors in the open ocean. The large contribution of the WBCs to the local ocean heat budget reflects their large role in the global poleward transport of heat.

However, a comparison of the heat budgets of the GS and KE (Fig. 17) suggests some differences in the causes of heat storage anomalies. In the GS the relatively large heat storage anomalies are clearly associated with advection plus diffusion, whereas in the $\mathrm{KE}$, the balance is more complex. The larger contributions of vertical isothermal motion reflect a larger role of wind-forced thermocline motion in the KE heat storage anomalies in these fixed-depth heat budgets.

\section{b. Wind forcing of the WBCs}

The relationship between winds and the large-scale ocean circulation and their impact on air-sea interaction have been the focus of numerous recent studies, particularly in the North Pacific (Xie et al. 2001; Schneider and Miller 2001; Seager et al. 2001; Qiu 2003; Kelly and Dong 2004) [See the discussion in Kwon et al. (2010).] Variability in North Pacific SSH has been well predicted by a one-and-a-half-layer ocean model that is responding to wind forcing (Qiu 2003): variations in PDO-related wind stress generate baroclinic Rossby waves that propagate into the KE region with a temporal lag of several years and alter the thermocline depth. Periods of positive SSH anomalies south of the KE front correspond to a depressed thermocline, a strong recirculation gyre, and a KE path that is stable. During periods of negative SSH anomaly, the $\mathrm{KE}$ weakens and cold-core eddies from north of the KE mix high-PV water into the SRG.

Although the circulation of the GS region is more complex, several aspects of the circulation are correlated with the NAO: GS path anomalies (Fig. 13) and changes in the DWBC that may cause GS path anomalies both lag the NAO (Joyce et al. 2000; Frankignoul et al. 2001). Westward-propagating Rossby waves are ubiquitous in the North Atlantic, as in the North Pacific; however, they do not contribute in a straightforward way to the SSH anomaly south of the GS, as in the North Pacific (see Kwon et al. 2010, their Fig. 8); this difference in dynamics may be owing to the nearly zonal orientation of the KE, 

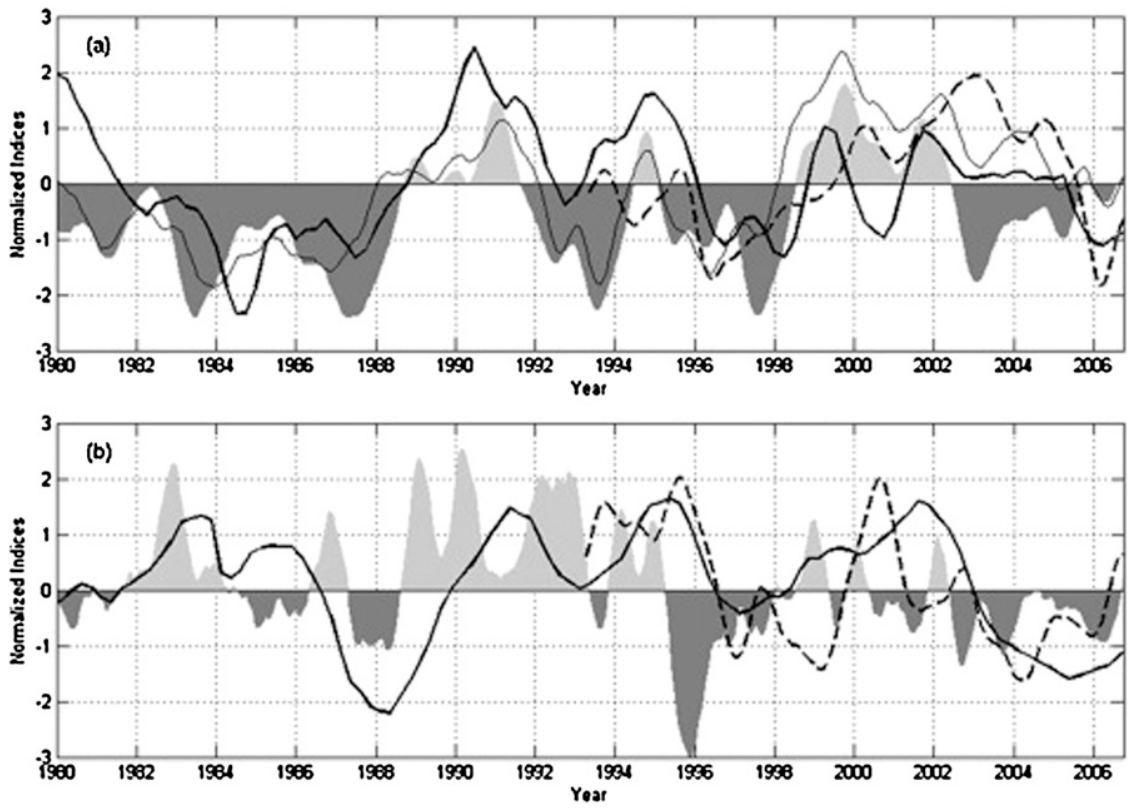

FIG. 13. Monthly path indices for the (a) Kuroshio Extension and the (b) Gulf Stream. Path from altimeter (dashed) from Figs. 12a,c, and T200 from hydrographic data (bold) after Joyce et al. (2000, 2009). Thin line in (a) is the SST index from Qiu et al. (2007). Shaded areas are the monthly indices of (a) PDO and (b) NAO [from the U.K. Climatic Research Unit (CRU) station]. All indices are normalized by their standard deviations and are filtered to retain variability with periods longer than $1 \mathrm{yr}$. Only the most recent part of a 50-yr record is shown to allow comparisons of the various indices.

compared with the northeast-trending GS. Anomalies in the Florida Current transport at $26^{\circ} \mathrm{N}$ have been shown to be negatively correlated with the NAO; the negative correlation is related to a reversal in the sign of the NAOrelated wind stress curl at this latitude (DiNezio et al. 2009).

Some additional evidence of a connection between the WBCs and winds comes from an analysis of a 50-yr record of heat content (Kelly and Dong 2004). The dominant mode of variability reveals GS and KE heat content anomalies that are in phase with each other and that lag the Arctic Oscillation by about 1 yr (see Fig. 22 in Kwon et al. 2010). The correlation between heat storage rate anomalies and ocean advection (Fig. 17) suggest that a wind-forced spinup of the WBCs is causing heat content changes by advection. However, there are puzzling aspects to this theory; in particular, the 1-yr lag is shorter than the expected delay for a baroclinic response of ocean circulation to winds.

\section{c. STMW: The intersection of dynamics and thermodynamics}

STMW is central to understanding air-sea interaction in the WBC regions because it is a heat reservoir that integrates both ocean and atmospheric forcing and therefore contributes to climate memory. A thick layer of STMW corresponds to low ocean stratification (low PV), low heat content, and low surface temperatures (Kwon 2003).
Because more STMW corresponds to less heat content, STMW is actually a "heat deficit" reservoir. The classical explanation for STMW is that wintertime air-sea fluxes create cold, deep mixed layers; the cold water from the mixed layer is then subducted into the thermocline where it forms a thick isothermal layer (Worthington 1976; Warren 1972). Part of the STMW is subsequently dissipated or advected away from the region. In contrast, Dewar et al. (2005) and Samelson and Vallis (1997) have argued that the STMW structure is an intrinsic part of the quasi-steady subtropical gyre circulation, which forms the base of the ventilated thermocline, and the isothermal layer results from large-scale forcing rather than from local cooling.

STMW is below the mixed layer for most of the year, capped by warmer waters. In the fall and early winter large fluxes erode the seasonal ocean stratification and rapidly decrease the SST. Once STMW is exposed to the surface in a deep mixed layer, the ocean has enormous thermal inertia: large fluxes are required to further lower the SST. The heat deficit of the STMW is so large that it cannot be depleted in a single warm year (Warren 1972); thus, STMW formed in previous years can interact with the atmosphere in subsequent winters through entrainment. Air-sea fluxes force a large seasonal signal in both STMW and heat content; however, as shown by the heat 
(a) Kuroshio Extension

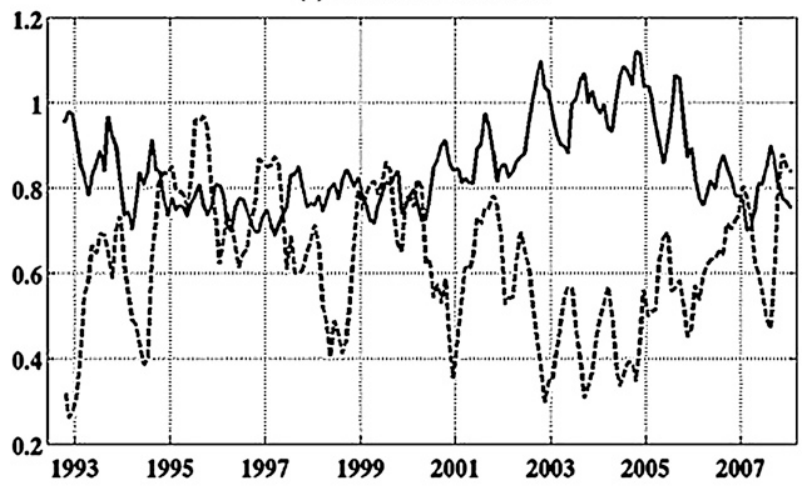

(b) Gulf Stream

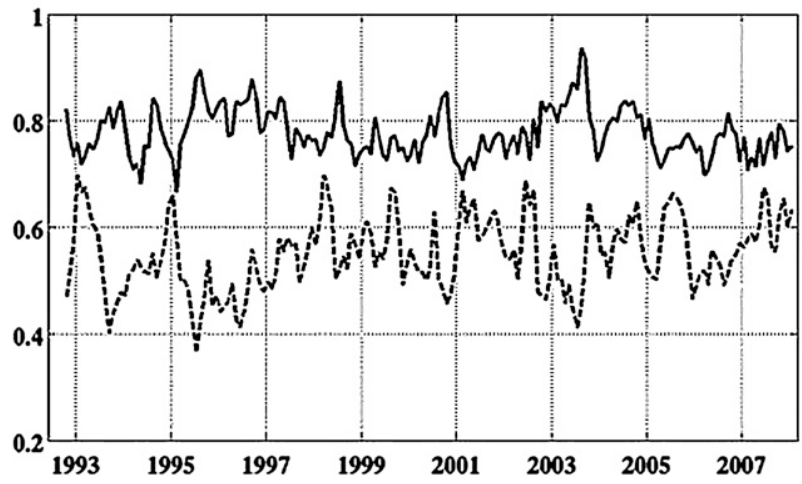

FIG. 14. Relationship of path stability and jet strength for (top) $\mathrm{KE}$ and (bottom) GS. Index of surface transport (solid), repeated from Fig. 12 for KE and GS, respectively. Index of zonally averaged path stability (dash). Path stability is the standard deviation of the path latitude over a 3-month period and is negatively correlated with the SSH difference across the jet (surface transport) for both WBCs: $\rho=-0.65(-0.47)$ for the GS (KE), which is significant at the $99 \%$ level.

budget analyses described in section $4 \mathrm{a}$ and Fig. 17, anomalies of advection of warm water into the region by the WBCs make a large contribution to the interannual variations in heat content.

Recent studies have examined the source of anomalies in the STMW volume in the KE, where changes in the dynamic ocean state have a profound impact on STMW. Figures 18a,b show the time series of upper-ocean temperature and $\mathrm{PV}$ as a function of time and depth, averaged over the SRG (Qiu and Chen 2006). STMW is identifiable in the figure by the low PV beneath the surface mixed layer. Increased STMW thickness was observed in 1993 96 and again in 2002-05 when the KE path was stable (Fig. 18c). During years when the KE path was unstable (and the thermocline shoaled), increased mixing from ring formation caused cross-frontal exchange and reduced the thickness of the STMW (Qiu et al. 2007). However, there is no clear correspondence between deep wintertime mixed layers (a condition for STMW formation) and net surface heat flux loss (Fig. 18d). This result, based on available CTD, XBT, and profiling float data, is confirmed by the concurrent surface ocean and air-sea flux measurements made by the KEO mooring (Cronin et al. 2008). Instead, Qiu and Chen (2006) show that the development of the winter mixed layer depth depends not only on the cumulative net surface heat flux, but also on the local upper-ocean stratification in the fall, which is increased by the mixing of high-PV water across the KE. Thus, preconditioning (stratification) is an important factor in STMW thickness anomalies.

It is not clear which processes are primarily responsible for anomalies of STMW in the GS region, which is also called Eighteen-Degree Water (EDW), owing to its stable temperature. Joyce et al. (2000) compared STMW and thermocline depth for more than $40 \mathrm{yr}$ at Bermuda and concluded that the two variables are uncorrelated, in contrast with the KE region results. Dong et al. (2007) found that variations in STMW layer thickness near the GS are more closely related to changes in warm-water advection than to air-sea flux anomalies. Analyses of the observations from CLIMODE are expected to improve our understanding of the processes governing EDW anomalies.

\section{d. Ocean forcing of air-sea fluxes}

Although seasonal variations in heat content anomalies are forced by air-sea fluxes, oceanic heat content modulates interannual variations in turbulent fluxes over the WBCs, as suggested by their relationship to SSH anomalies. SSH in the WBC regions is a good proxy for upperocean heat content because temperature effects generally dominate over salinity effects on density in the subtropical gyre; accordingly, altimetric SSH is used to extrapolate the relatively sparse estimates of heat content from Argo floats (Willis et al. 2004). In the WBCs positive anomalies of SSH are associated with higher heat content in the upper $800 \mathrm{~m}$ of the ocean (Vivier et al. 2002; Dong and Kelly 2004).

Large turbulent flux anomalies are caused by changes in WBC paths, consistent with the SST response to the path indices seen in Fig. 16; to distinguish the effects of heat content from those of path changes, Lagrangian estimates of heat content and fluxes are examined here. Both fluxes and SSH were averaged over the region from $2^{\circ}$ to $7^{\circ}$ latitude south of the time-varying GS or KE path. Turbulent fluxes were estimated from National Centers for Environmental Prediction (NCEP)/Department of Energy (DOE) Global Reanalysis 2 (NCEP-2; Kistler et al. 2001) variables in the Coupled Ocean-Atmosphere Response Experiment (COARE; Fairall et al. 1996) bulk algorithm. (Note that oceanographic convention is used here: negative fluxes correspond to heat loss from the ocean.) The effect of heat content can be seen by the correlation between the turbulent fluxes and SSH (Fig. 19). In the GS 

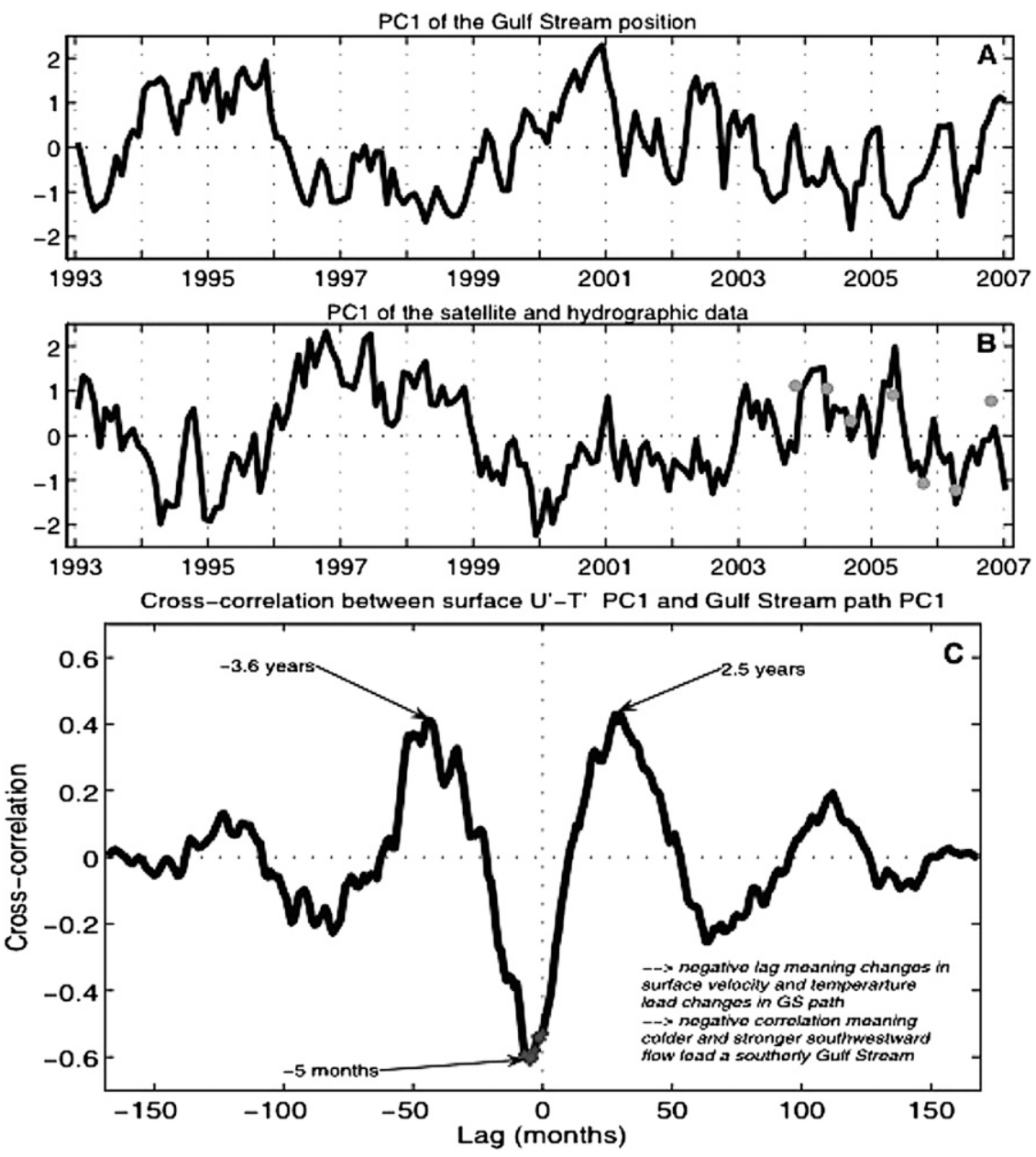

FIG. 15. Principal components of (a) GS path and (b) slope water SST/surface flow, and (c) lagged correlations showing that changes in the GS northern recirculation gyre strength (here equated with the magnitude of southwesterly slope water flow) precede changes in GS path (Peña-Molino and Joyce 2008).

region, as the heat content (SSH) increases, the amount of heat fluxed to the atmosphere increases; flux anomalies lag heat content by approximately 3 months, which is likely related to the seasonal cycle of the ocean mixed layer. In the summer STMW heat content anomalies are isolated from the atmosphere by a warm, shallow mixed layer; in the fall, heat content anomalies are entrained into the mixed layer as it deepens (Alexander and Deser 1995). In the KE the correlation is also negative, but it is not statistically significant over the 15 -yr altimeter record. However, using heat content over $50 \mathrm{yr}$, Kelly (2004) found that heat content anomalies in the KE region have some skill in predicting air-sea heat fluxes.

\section{Discussion}

We have presented some detailed descriptions of the GS and KE current systems here, along with summaries of the current state of knowledge of the air-sea interaction over these WBC frontal systems. There are numerous processes that link the atmosphere and the ocean; here, we have emphasized the frontal-scale processes and interactions, while large-scale atmosphere-ocean interaction and their implications for climate change are discussed by Kwon et al. (2010). All of the frontal-scale processes are occurring in both the KE and the GS systems, but the relative importance of these processes may be different in the two systems.

\section{a. Ocean state}

The need to understand what determines the ocean state is critical in establishing whether there are coupled interactions and in predicting climate variability and change. Explanations for WBC variability include both dynamical and thermodynamic processes, which differ for the GS and the KE regions. 
(a) GS path

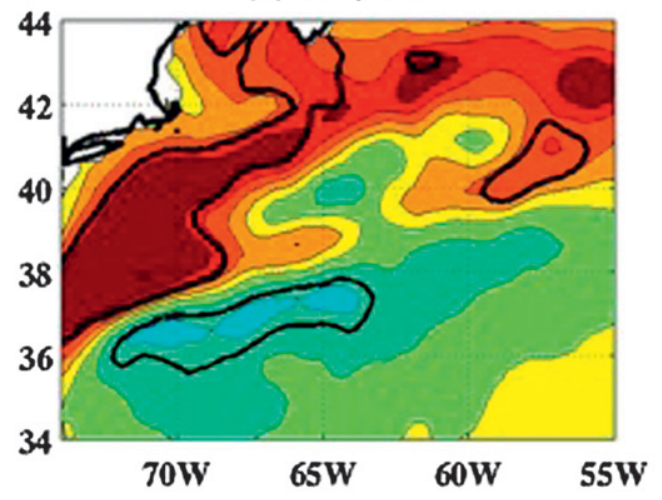

(c) KE path

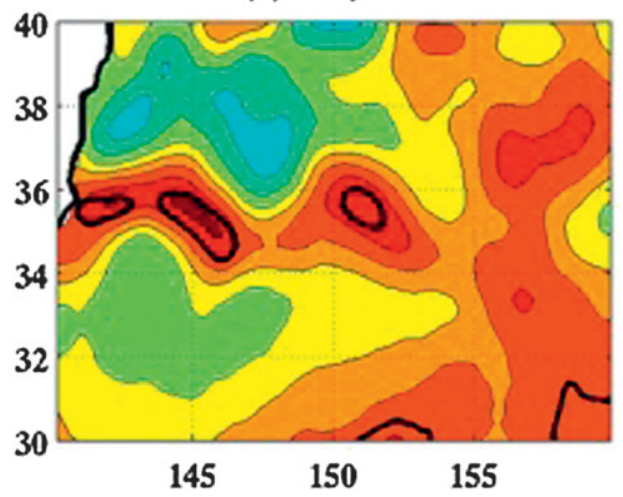

(b) GS transport

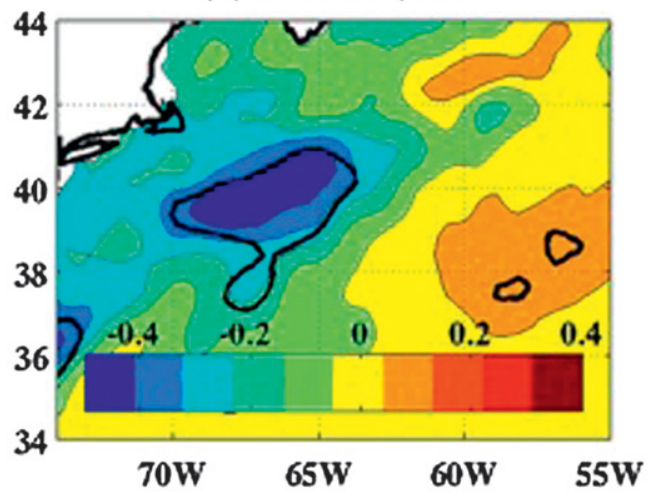

(d) KE transport

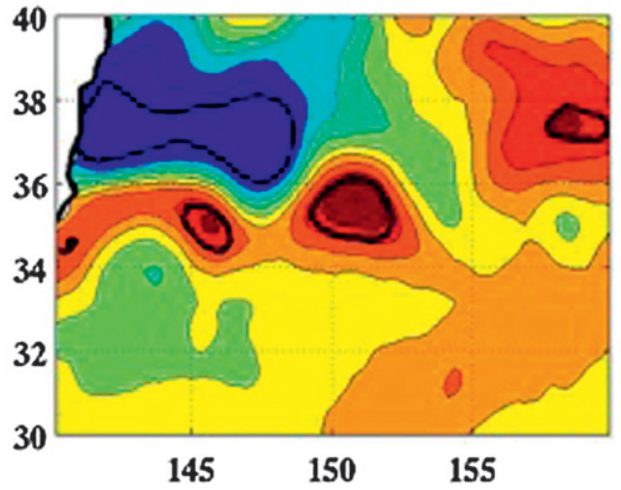

FIG. 16. SST response to changes in zonally averaged indices in Fig. 12. SST anomalies corresponding to an increase of one standard deviation in (a) path latitude and (b) eastward transport of the Gulf Stream. Dark contours enclose the regions where correlations with the indices exceed $95 \%$ confidence level of 0.23 . (c),(d) As in (a),(b), but for the Kuroshio Extension with the $95 \%$ confidence level of 0.31 . Color bar in (b) applies to all panels, with units of ${ }^{\circ} \mathrm{C}$.

Changes in the WBCs themselves force large local changes in SST (Fig. 16), which in turn contribute to changes in fluxes (Figs. 2 and 3). WBC changes are characterized by anomalies of path latitude and jet strength (Fig. 12); path anomalies in the KE are substantially larger and have lower frequencies. Relationships between path and path stability (the amount of meandering) are similar in both regions (Fig. 14); stronger jets meander less. Transport anomalies in both WBCs are associated with changes in the NRG (Figs. 15 and 16).

Changes in the volume of STMW are clearly linked to air-sea interaction, although the causes and implications are different for the GS and KE. The differences may be owing to differing thermocline depths, with the deeper thermocline in the GS region allowing a larger heat storage capacity and the shallower thermocline in the KE region increasing the contribution of thermocline motion to heat storage (Fig. 17). An estimate of the volume of the heat storage reservoir can be made from the climatological March mixed layer depths [see Qiu and Huang (1995), their Figs. 5b and 9b]: mixed layers typically reach $250 \mathrm{~m}$ for the GS versus $150 \mathrm{~m}$ for the KE. In analogy with a water reservoir, a system with a large amount of storage $H$ will differ markedly from one with little storage, which can be seen by examining a simple heat budget, $\partial H / \partial t=Q+$ advection. In the limit of no storage, heat advection (lateral inflow) must balance heat loss $Q$ through the surface. Consistent with this interpretation, a recent study by Kwon and Deser (2007) suggests that air-sea flux anomalies in the $\mathrm{KE}$ are closely related to a convergence of heat transport (advection), rather than to heat content. On the other hand, in a system with more storage, inflow anomalies can be absorbed by the reservoir unless several seasons of strong inflow fill the reservoir, triggering a discharge of excess heat. Thus, in the GS flux anomalies $Q$ will be more closely associated with heat content $H$ than with advection (Fig. 19a). The GS relationships are depicted schematically in Fig. 20: an increase in heat advection over several years causes an accumulation of heat (a decrease in STMW volume) and a larger discharge of heat to the atmosphere. 


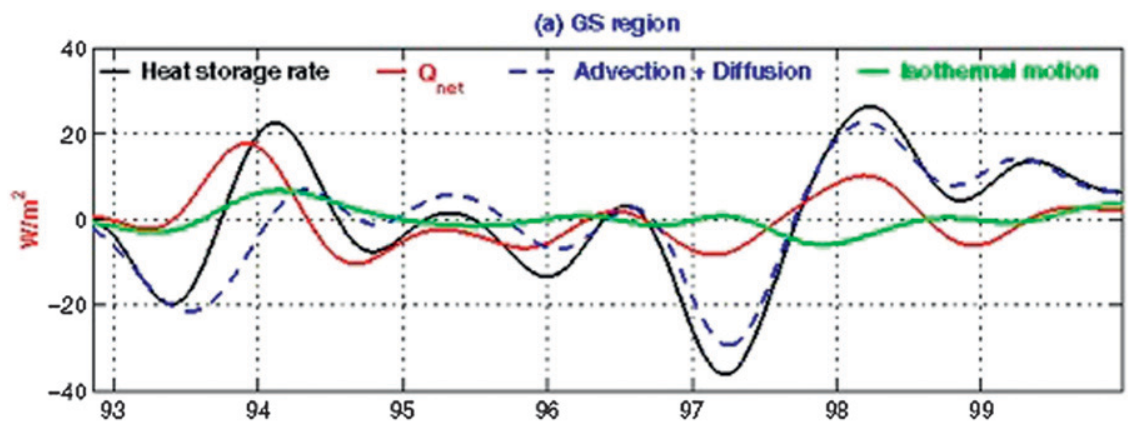

(b) KE region

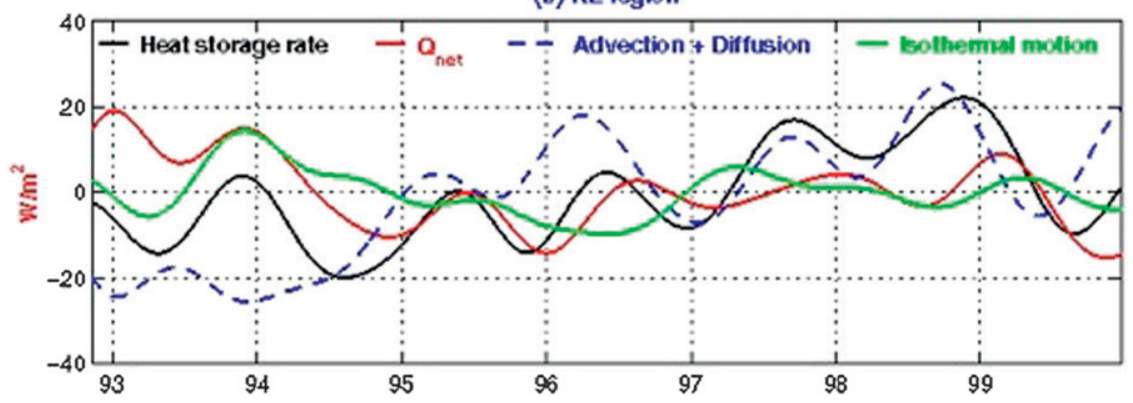

FIG. 17. Heat storage rate for the western boundary current regions in the upper $800 \mathrm{~m}$; (a) GS and (b) KE. Heat storage rate (black), net surface heat flux (red), advection/diffusion (blue dashed), and Ekman pumping (green). Adapted from Vivier et al. (2002) and Dong and Kelly (2004).

Adding a fluctuating depth (thermocline motion) to a shallow reservoir makes heat storage a complicated function of inflow, outflow, and the changing storage volume; this would account for the more complicated heat budget in the KE region (Fig. 17b). In the KE, observed SSH anomalies and STMW volume changes can be largely accounted for by wind-forced ocean dynamics (Qiu and Chen 2005, 2006). Decreases in STMW volume are caused by cross-frontal mixing associated with unstable KE paths; path stability is in turn related to wind-driven anomalies in the thermocline, with a lag corresponding to the ocean adjustment time by Rossby waves. In contrast, while several aspects of GS variability are linked statistically to the NAO (Frankignoul et al. 2001), anomalies of the complex circulation of the North Atlantic are much more difficult to model. Further, no comparable simple theory relating STMW volume anomalies to WBC characteristics has been established, although this is a goal of ongoing CLIMODE analyses.

Eddies may play a central role in increasing STMW volume anomalies, which is a central hypothesis of CLIMODE. KESS analyses suggest that eddies associated with KE path stability mix high-PV water into the SRG region, reducing the volume of STMW. Detailed analyses of EDW formation and evolution are not yet available from CLIMODE from which to compare processes with those in the KE.
However, because the strength of the WBCs is anticorrelated with the meandering (Fig. 14), increased advection of warm water into the region likely corresponds to fewer eddies; therefore, there may also be a synergy between the large-scale wind-forced circulation and eddies in EDW formation.

\section{b. Impact on atmosphere}

Several aspects of the WBCs may contribute to the air-sea interaction: the strength and location of the SST gradient of the WBC itself, which in turn is related to advection and heat storage, and the land-sea contrast, which is the difference between the warm core of the WBC and the colder air over land. In addition, the impact of the WBCs may depend on the atmospheric state, including other large-scale climate factors.

The SST fronts of the WBCs modify atmospheric stability and enhance the low-level baroclinicity in the atmosphere, a factor that will likely increase synoptic storm activity. Nakamura et al. (2004) concluded that the KOE front anchored the storm track when the jet stream is relatively weak. Changes in the strength and stability of the WBCs (Fig. 14) may be important in determining lowlevel baroclinicity before a storm system develops, that is, in preconditioning the atmosphere for cyclogenesis. Joyce et al. (2009) show that the winter surface "storm track" 
(a) Temperature in Recirculation Gyre

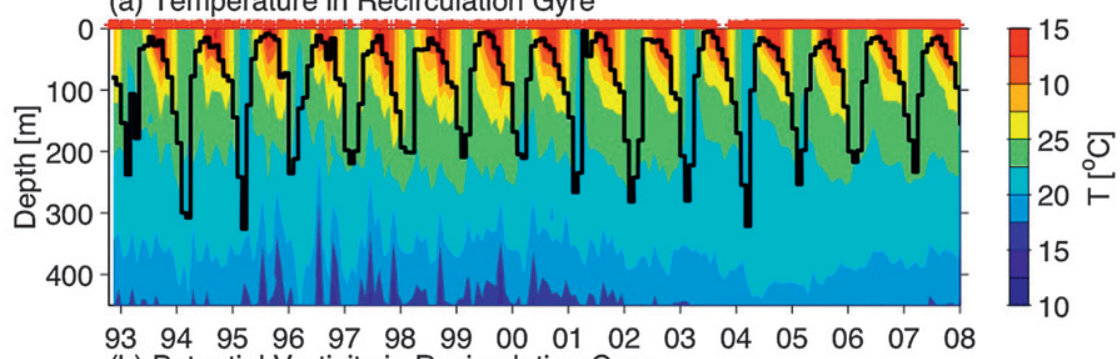

(b) Potential Vorticity in Recirculation Gyre

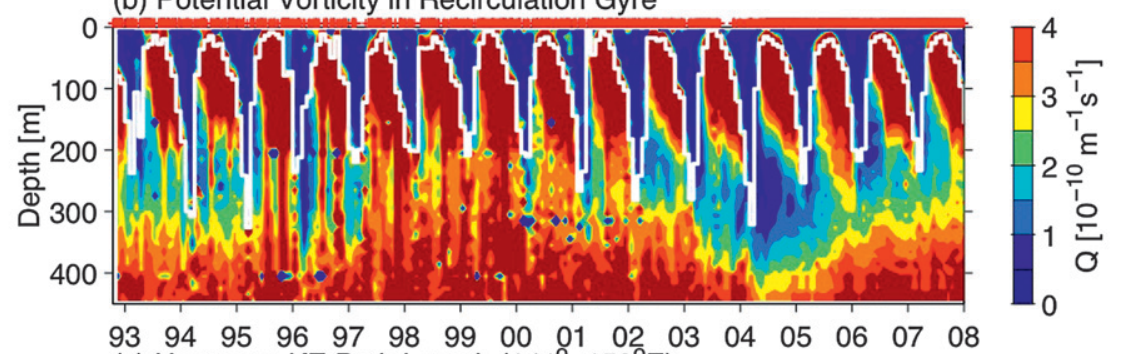

(c) Upstream KE Path Length $\left(141^{\circ}-153^{\circ} \mathrm{E}\right)$

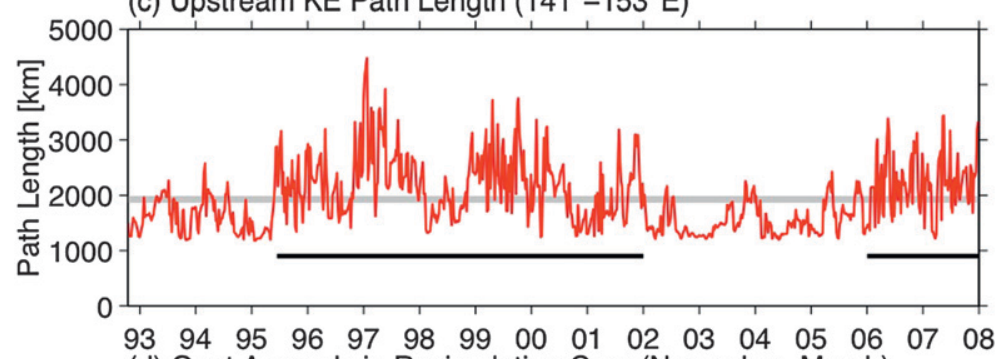

(d) Qnet Anomaly in Recirculation Gyre (November-March)

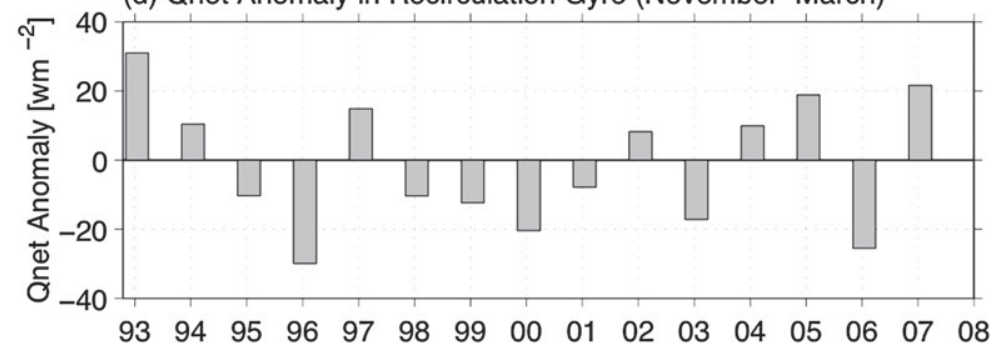

FIG. 18. Monthly time series of (a) temperature and (b) potential vorticity averaged over the SRG. The thick black and white lines in (a) and (b) denote the base of the mixed layer. Red crosses indicate the individual temperature profiles used in constructing the monthly $T(z, t)$ profiles. (c) The KE pathlength is integrated over $141^{\circ}-153^{\circ} \mathrm{E}$. Bold lines indicate unstable periods. (d) Net surface heat flux anomalies are averaged over the cooling season (NovemberMarch). Adapted from Qiu and Chen (2006).

responds to interannual changes in both $\mathrm{KE}$ and GS paths. Seasonal temperature changes are likely important: the WBC warm core has a much weaker seasonal cycle than the colder waters or the air. The largest fluxes and associated cloud patterns may migrate offshore through the winter as shelf waters cool (Young and Sikora 2003).

Atmospheric circulation patterns such as the NAO and Pacific-North American pattern (PNA) modify the jet stream and the relative location of the jet stream and WBC. This may help determine whether the WBCs are important to synoptic storm development (S. Businger
2007, personal communication). Joyce et al. (2009) speculated that differences between the atmospheric responses to the KE and GS may be in part related to the more zonal orientation of the KE and the stronger SST signals of the GS, but may also reflect differences in mean storm tracks/ WBC path geometry.

A central open question is the extent to which the WBCs themselves induce a deep-tropospheric response. There are some hints from recent studies (Minobe et al. 2008) that frontal-scale effects over the GS may be felt well above the boundary layer, and that the planetary 

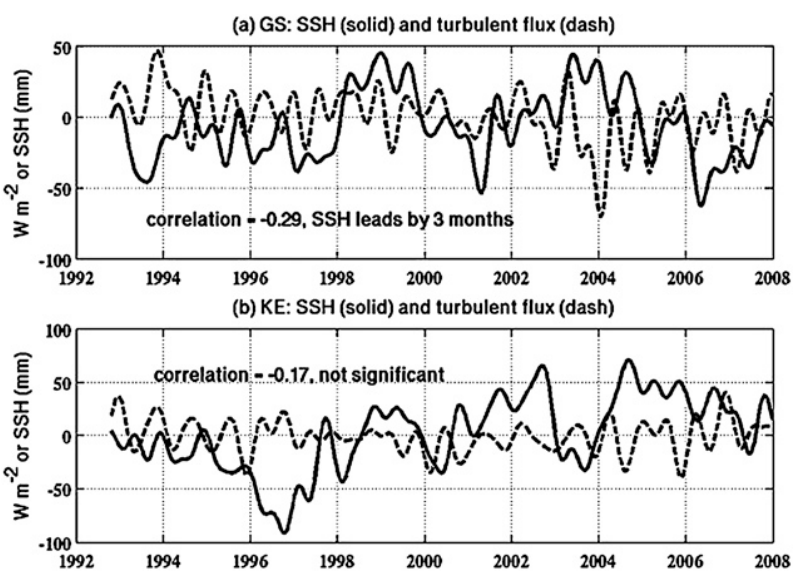

FIG. 19. Flux response to heat content. (a) SSH (as a proxy for upper-ocean heat content) is anticorrelated with the turbulent flux anomaly (flux into the ocean is positive) south of the GS. Positive SSH anomalies (high heat content) lead negative flux anomalies (heat flux out of the ocean) by about 3 months. (b) A negative correlation in the KE region is not statistically significant. Nonseasonal flux and SSH anomalies are averaged over a region from $2^{\circ}$ to $7^{\circ}$ latitude south of the mean axis of the WBC over a region from $72^{\circ}$ to $52^{\circ} \mathrm{W}$ and from $142^{\circ}$ to $160^{\circ} \mathrm{E}$ for the GS and KE, respectively.

wave response may be energetic enough to affect the large-scale westerly jet structure. On the other hand, the mean vertical velocities associated with the boundary layer interactions are not large, and their influence may be weak relative to the vertical velocities associated with baroclinic development in the storm track. However, the simulations of Minobe et al. (2008) were based on annual climatologies of diabatic heating, so that they may underestimate the effect on synpotic time scales.

\section{c. Ocean-atmosphere coupling}

The possibility of a coupled response remains an unresolved issue for midlatitude air-sea interaction, as discussed by Kwon et al. (2010). We have highlighted specific differences between the KE and the GS here related to ocean-atmosphere coupling. The impact of wind forcing on the KE appears to be relatively simple (Qiu and Chen 2005), but feedback to the atmosphere appears relatively weak (Fig. 19b). On the other hand, the impact of winds on the GS is more complex, characterized primarily by correlations with the NAO (Joyce et al. 2000; Frankignoul et al. 2001; Kelly and Dong 2004; PeñaMolino and Joyce 2008); however, the impact of heat stored in the GS region on air-sea fluxes can be clearly seen, with heat content leading the fluxes (Fig. 19a).

The use of SST in many climate studies is convenient, but problematic, as discussed in section $4 \mathrm{a}$, and may bias interpretations of air-sea coupling. Upper-ocean heat content better represents the heat that is available to the
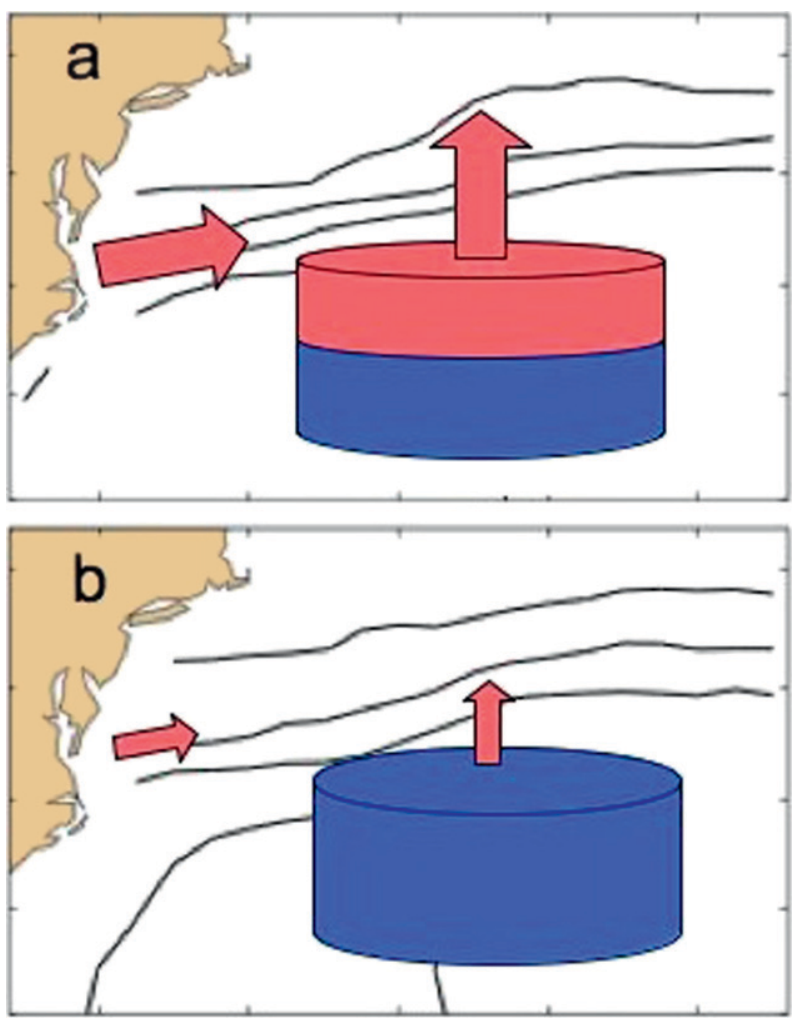

FIG. 20. Dynamics and thermodynamics in the Gulf Stream region. (a) Increased heat advection by the GS (arrow, left) causes an accumulation of heat in the southern recirculation gyre, capping over the STMW with warmer water (red upper volume). (b) Decreased heat advection preconditions the ocean for more STMW formation, increasing the volume of STMW (blue volume). Greater heat content tends to increase the heat loss to the atmosphere (upward arrow), as in Fig. 19a. The GS heat storage capacity creates a complex balance between advection and heat loss. Adapted from Dong (2004).

atmosphere from the WBCs (Deser et al. 2003) and better represents the contribution of the ocean to climate memory. There are both substantial interannual variations in heat content and differences between the KE and the GS in heat storage capacity.

\section{d. The way forward}

There are many remaining questions about the dynamics and thermodynamics of the WBCs, their impact on the atmosphere, the potential for ocean-atmosphere coupling, and the implications for climate change. Some questions that suggest research directions are as follows:

(i) WBC anomalies: Which aspects of WBC variability are the most important in air-sea interaction? How do differences between the GS and the KE, especially in STMW, affect air-sea interaction?

(ii) Marine boundary layer: To what extent does stability dominate the effects of WBCs on the boundary 
layer? What determines the vertical penetration of WBC effects? How important is the land-sea temperature contrast?

(iii) Storm and atmosphere impact: On what temporal and spatial scales does WBC variability influence the marine boundary layer and troposphere? Is preconditioning by the WBCs a critical factor in storm intensification? What factors affect the ability of WBCs to anchor storms?

(iv) Modeling and observations: How well do climate models reproduce the observed WBC characteristics and the atmospheric response? Can the models characterize the dynamics and thermodynamics of the different WBC regions?

\section{Summary}

We have presented both a review of recent work in air-sea interaction over the WBCs and contrasting observational descriptions of the KE and GS regions, with the goal of defining and motivating promising areas of research into air-sea interaction in the midlatitudes. There is much evidence that the cross-frontal SST gradients in the GS and KE have large impacts on the local and regional structures of the marine boundary layer and on the lower atmosphere, although it is not clear how interannual-to-decadal variations in WBCs affect the atmosphere. Further, the WBCs intensify cyclogenesis and anchor storm-track locations. There is also recent evidence of an impact on the deep troposphere.

We have shown that there are substantial similarities in the GS and KE systems, although the two systems appear to differ in which dynamical and thermodynamic processes dominate. Similarities include a robust anticorrelation between path stability and surface transport, similar effects of WBC and NRG anomalies on SST, the importance of geostrophic advection to the heat budget, and the magnitude of air-sea heat fluxes. Differences include the straightforward response of the KE to largescale wind forcing versus the more nuanced relationship of the GS to the winds through the large-scale circulation, the importance of wind-forced thermocline motion in STMW anomalies in the KE, and the greater impact of heat content in the GS on air-sea fluxes of heat. Ongoing analyses of CLIMODE observations are expected to clarify and expand these similarities and differences.

Essential questions remain, however, regarding the links between the ocean and atmospheric processes, the space and time scales over which they operate, and the role of WBC anomalies in the climate system. It is not yet clear how the time-varying WBCs or the differences between the GS and KE affect the regional air-sea interaction and atmospheric responses. However, we hope that an understanding of the essential elements of WBC variability and the contrasts between the KE and the GS will lead to new insights into the roles of the WBCs in the climate system.

Acknowledgments. KAK was supported by NASA Contracts 1267196 and NNX08AR30G and by NSF Grant OCE-0424912 (CLIMODE). RMS was supported by NSF Grant OCE-0424516. BQ was supported by NSF Grant OCE-0220680 and by NASA Contract 1207881. TJ was supported by NSF Grant OCE-0424865. Y-OK was supported by the Claudia Heyman Fellowship of the WHOI Ocean Climate Change Institute.

\section{REFERENCES}

Alexander, M., and C. Deser, 1995: A mechanism for the recurrence of midlatitude SST anomalies during winter. J. Phys. Oceanogr., 25, 122-137.

Barsugli, J. J., and D. S. Battisti, 1998: The basic effects of atmosphere-ocean thermal coupling on midlatitude variability. J. Atmos. Sci., 55, 477-493.

Bengtsson, L., K. Hodges, and E. Roeckner, 2006: Storm tracks and climate change. J. Climate, 19, 3518-3543.

Booth, J. F., L. A. Thompson, J. Patoux, K. A. Kelly, and S. Dickinson, 2010: The signature of the midlatitude tropospheric storm tracks in the surface winds. J. Climate, 23, 1160-1174.

Brown, W., and J. Edson, 2009: The atmospheric response to the North Atlantic Gulf Stream observed by a ship-board wind profiler. Proc. Eighth Int. Symp. of Tropospheric Profiling, Delft, The Netherlands, ISTP, S12-O06.

Businger, S., T. M. Graziano, M. L. Kaplan, and R. A. Rozumalski, 2005: Cold-air cyclogenesis along the Gulf Stream front: Investigation of diabatic impacts on cyclone development, frontal structure and track. Meteor. Atmos. Phys., 88, 65-90.

Cayan, D. R., 1992: Latent and sensible heat flux anomalies over the northern oceans: Driving the sea surface temperature. J. Phys. Oceanogr., 22, 859-881.

Chang, E. K. M., S. Lee, and K. L. Swanson, 2002: Storm track dynamics. J. Climate, 15, 2163-2183.

Chelton, D. B., M. Schlax, M. Freilich, and R. Milliff, 2004: Satellite measurements reveal persistent small-scale features in ocean winds. Science, 303, 978-983.

Chen, S.-J., Y.-H. Kuo, P.-Z. Zhang, and Q.-F. Bai, 1992: Climatology of explosive cyclones off the East Asian coast. Mon. Wea. Rev., 120, 3029-3035.

Cione, J. J., S. Raman, and L. J. Pietrafesa, 1993: The effect of Gulf Stream-induced baroclinicity on U.S. East Coast winter cyclones. Mon. Wea. Rev., 121, 421-430.

The CLIMODE Group, 2009: The CLIMODE Field Campaign: Observing the cycle of convection and restratification over the Gulf Stream. Bull. Amer. Meteor. Soc., 90, 1337-1350.

Colucci, S. J., 1976: Winter cyclone frequencies over the eastern United States and adjacent western Atlantic, 1964-1973. Bull. Amer. Meteor. Soc., 57, 548-553.

Cornillon, P., 1986: The effect of the New England seamounts on Gulf Stream meandering as observed from satellite IR imagery. J. Phys. Oceanogr., 16, 386-398.

_ , and K.-A. Park, 2001: Warm core ring velocities inferred from NSCAT. Geophys. Res. Lett., 28, 575-578. 
Cronin, M. F., C. Meinig, C. L. Sabine, H. Ichikawa, and H. Tomita, 2008: Surface mooring network in the Kuroshio Extension. IEEE Syst. J., 2, 424-430.

Deser, C., J. J. Bates, and S. Wahl, 1993: The influence of sea surface temperature gradients on stratiform cloudiness along the equatorial front in the Pacific Ocean. J. Climate, 6, 11721180.

_- M. A. Alexander, and M. S. Timlin, 2003: Understanding the persistence of sea surface temperature anomalies in midlatitudes. J. Climate, 16, 57-72.

Dewar, W., R. Samelson, and G. Vallis, 2005: The ventilated pool: A model for subtropical mode water. J. Phys. Oceanogr., 35, 137-150.

DiNezio, P., L. Gramer, W. Johns, C. Meinen, and M. Baringer, 2009: Observed interannual variability of the Florida Current: Wind forcing and the North Atlantic Oscillation. J. Phys. Oceanpgr., 39, 721-736.

Dong, S., 2004: Interannual variations in upper ocean heat content and heat transport convergence in the western North Atlantic. $\mathrm{Ph} . \mathrm{D}$. thesis, University of Washington, $152 \mathrm{pp}$.

— , and K. A. Kelly, 2003: Seasonal and interannual variations in geostrophic currents in the Middle Atlantic Bight. J. Geophys. Res., 108, 3172, doi:10.1029/2002JC001357.

— and - 2004: The heat budget in the Gulf Stream region: The importance of heat storage and advection. J. Phys. Oceanogr., 34, 1214-1231.

_ - S. Hautala, and K. A. Kelly, 2007: Interannual variations in upper ocean heat content and heat transport convergence in the western North Atlantic. J. Phys. Oceanogr., 37, 2682-2697.

Doyle, J. D., and T. T. Warner, 1990: Mesoscale coastal processes during GALE IOP 2. Mon. Wea. Rev., 118, 283-308.

Ezer, T., 1994: On the interaction between the Gulf Stream and the New England Seamount Chain. J. Phys. Oceanogr., 24, 191-204.

Fairall, C. W., E. F. Bradley, D. P. Rogers, J. B. Edson, and G. S. Young, 1996: Bulk parameterization of air-sea fluxes for Tropical Ocean-Global Atmosphere Coupled-Ocean Atmosphere Response Experiment. J. Geophys. Res., 101, 3747-3764.

Frankignoul, C., G. de Coëtlogon, T. M. Joyce, and S. Dong, 2001: Gulf Stream variability and ocean-atmosphere interactions. J. Phys. Oceanogr., 31, 3516-3529.

Giordani, H., and G. Caniaux, 2001: Sensitivity of cyclogenesis to sea surface temperature in the northwestern Atlantic. Mon. Wea. Rev., 129, 1273-1295.

Hanawa, K., and L. D. Talley, 2001: Mode waters. Ocean Circulation and Climate, G. Siedler, J. Church, and J. Gould, Eds., International Geophysics Series, Vol. 77, Academic Press, 373-386.

Hogg, N. G., R. S. Pickart, R. M. Hendry, and W. J. Smethie Jr., 1986: The northern recirculation gyre of the Gulf Stream. Deep-Sea Res., 33, 1139-1165.

Holt, T. R., and S. Raman, 1992: Three-dimensional mean and turbulence structure of a coastal front influenced by the Gulf Stream. Mon. Wea. Rev., 120, 17-39.

Holton, J. R., 2004: An Introduction to Dynamical Meteorology. 4th ed. Elsevier Academic Press, 535 pp.

Hoskins, B. J., and P. J. Valdes, 1990: On the existence of storm tracks. J. Atmos. Sci., 47, 1854-1864.

—_, and K. I. Hodges, 2002: New perspectives on the Northern Hemisphere winter storm tracks. J. Atmos. Sci., 59, 1041-1061.

Hurlburt, H. E., and E. J. Metzger, 1998: Bifurcation of the Kuroshio Extension at the Shatsky Rise. J. Geophys. Res., 103, 7549-7566.
Hurrell, J. W., Y. Kushnir, G. Ottersen, and M. Visbeck, 2003: An overview of the North Atlantic Oscillation. The North Atlantic Oscillation, Geophys. Monogr., Vol. 134, Amer. Geophys. Union, 1-35.

Jayne, S. R., and Coauthors, 2009: The Kuroshio Extension and its recirculation gyres. Deep-Sea Res. I, 56, 2088-2099.

Joyce, T. M., C. Deser, and M. A. Spall, 2000: The relation between decadal variability of Subtropical Mode Water and the North Atlantic Oscillation. J. Climate, 13, 2550-2569.

—, Y.-O. Kwon, and L. Yu, 2009: On the relationship between synoptic wintertime atmospheric variability and path shifts in the Gulf Stream and the Kuroshio Extension. J. Climate, 22, 3177-3192.

Kalnay, E., and Coauthors, 1996: The NCEP/NCAR 40-Year Reanalysis Project. Bull. Amer. Meteor. Soc., 77, 437-471.

Kelly, K. A., 2004: The relationship between oceanic heat transport and surface fluxes in the western North Pacific. J. Climate, 17, 573-588.

—, and S. T. Gille, 1990: Gulf Stream surface transport and statistics at $69^{\circ} \mathrm{W}$ from the GEOSAT altimeter. J. Geophys. Res., 95, 3149-3161.

— Atlantic. Part II: The upper-ocean heat budget. J. Phys. Oceanogr., 25, 2361-2373.

, and S. Dong, 2004: The relationship of western boundary current heat transport and storage to mid-latitude oceanatmosphere interaction. Earth's Climate: The Ocean-Atmosphere Interaction, Geophys. Monogr., Vol. 147, Amer. Geophys. Union, 347-363.

, S. Dickinson, M. J. McPhaden, and G. C. Johnson, 2001: Ocean currents evident in satellite wind data. Geophys. Res. Lett., 28, 2469-2472.

— L. Thompson, W. Cheng, and E. J. Metzger, 2007: Evaluation of HYCOM in the Kuroshio Extension region using new metrics. J. Geophys. Res., 112, C01004, doi:10.1029/ 2006JC003614.

Kistler, R., and Coauthors, 2001: The NCEP-NCAR 50-Year Reanalysis: Monthly means CD-ROM and documentation. Bull. Amer. Meteor. Soc., 82, 247-268.

Kobashi, F., S.-P. Xie, N. Iwasaka, and T. T. Sakamoto, 2008: Deep atmospheric response to the North Pacific oceanic subtropical front in spring. J. Climate, 21, 5960-5975.

Konda, M. H., H. Ichikawa, H. Tomita, and M. F. Cronin, 2010: Surface heat flux variations across the Kuroshio Extension as observed by surface flux buoys. J. Climate, 23, 5206-5221.

Kuo, Y.-H., R. J. Reed, and S. Low-Nam, 1991: Effects of surface energy fluxes during the early development and rapid intensification stages of seven explosive cyclones in the western Atlantic. Mon. Wea. Rev., 119, 457-475.

Kwon, Y.-O., 2003: Observation of general circulation and water mass variability in the North Atlantic subtropical mode water region. Ph.D. thesis, University of Washington, $161 \mathrm{pp}$

— , and C. Deser, 2007: North Pacific decadal variability in the Community Climate System Model version 2. J. Climate, 20, 2416-2433.

- M. A. Alexander, N. A. Bond, C. Frankignoul, H. Nakamura, B. Qiu, and L. Thompson, 2010: Role of the Gulf Stream and Kuroshio-Oyashio systems in large-scale atmosphere-ocean interaction: A review. J. Climate, 23, 3249-3281.

Liu, W. T., X. Xie, and P. P. Niiler, 2007: Ocean-atmosphere interaction over Agulhas extension meanders. J. Climate, 20, $5784-5797$. 
Maximenko, N. A., and P. P. Niiler, 2004: Hybrid decade-mean global sea level with mesoscale resolution. Recent Advances in Marine Science and Technology, N. Saxena, Ed., PACON International, 55-59.

Minobe, S., A. Kuwano-Yoshida, N. Komori, S.-P. Xie, and R. J. Small, 2008: Influence of the Gulf Stream on the troposphere. Lett. Nat., 452, 206-209.

Nakamura, H., and A. Shimpo, 2004: Seasonal variations in the Southern Hemisphere storm tracks and jet streams as revealed in a reanalysis dataset. J. Climate, 17, 1828-1844.

, T. Sampe, Y. Tanimoto, and A. Shimpo, 2004: Observed associations among storm tracks, jet stream and midlatitude oceanic fronts. Earth's Climate: The Ocean-Atmosphere Interaction, Geophys. Monogr., Vol.147, Amer. Geophys. Union, 329-345.

,-- , A. Goto, W. Ohfuchi, and S.-P. Xie, 2008: On the importance of midlatitude frontal zones for the mean state and dominant variability in the tropospheric circulation. Geophys. Res. Lett., 35, L15709, doi:10.1029/2008GL034010.

Norris, J. R., and C. B. Leovy, 1994: Interannual variability in stratiform cloudiness and sea surface temperature. J. Climate, 7, 1915-1925.

Peña-Molino, B., and T. Joyce, 2008: Variability in the slope water and its relation to the Gulf Stream path. Geophys. Res. Lett., 35, L03606, doi:10.1029/2007GL032183.

Persson, P. O. G., J. E. Hare, L. B. Nance, and B. Walter, 2008: Impact of air-sea interaction on extra-tropical cyclones. Proc. ECMWF Workshop on Ocean-Atmosphere Interactions, Reading, United Kingdom, ECMWF, 123-146. [Available online at http://www.ecmwf.int/publications/library/ecpublications/_pdf/ workshop/2008/Atmos_Ocean_Interaction/Persson.pdf.]

Qiu, B., 2000: Interannual variability of the Kuroshio Extension system and its impact on the wintertime SST field. J. Phys. Oceanogr., 30, 1486-1502.

_ 2003: Kuroshio Extension variability and forcing of the Pacific decadal oscillations: Responses and potential feedback. J. Phys. Oceanogr., 33, 2465-2482.

— , and K. A. Kelly, 1993: Upper-ocean heat balance in the Kuroshio Extension region. J. Phys. Oceanogr., 23, 2027-2041.

— and R. X. Huang, 1995: Ventilation of the North Atlantic and the North Pacific: Subduction versus obduction. J. Phys. Oceanogr., 25, 2374-2390.

- , and S. Chen, 2005: Variability of the Kuroshio Extension jet, recirculation gyre, and mesoscale eddies on decadal time scales. J. Phys. Oceanogr., 35, 2090-2103.

— North Pacific subtropical mode water: Oceanic versus atmospheric control. J. Phys. Oceanogr., 36, 1365-1380.

$\longrightarrow,-$, and P. Hacker, 2007: Effect of mesoscale eddies on subtropical mode water variability from the Kuroshio Extension System Study (KESS). J. Phys. Oceanogr., 37, 9821000 .

,,,--- N. Hogg, S. Jayne, and H. Sasaki, 2008: The Kuroshio Extension northern recirculation gyre: Profiling float measurements and forcing mechanism. J. Phys. Oceanogr., 38, 1764-1779.

Reynolds, R. W., T. M. Smith, C. Liu, D. B. Chelton, K. S. Casey, and M. G. Schlax, 2007: Daily high-resolution-blended analyses for sea surface temperature. J. Climate, 20, 54735496.

Samelson, R., and G. Vallis, 1997: Large-scale circulation with small diapycnal diffusion: The two-thermocline limit. J. Mar. Res., 55, 223-275.
Sampe, T., and S.-P. Xie, 2007: Mapping high sea winds from space: A global climatology. Bull. Amer. Meteor. Soc., 88, 1965-1978.

Sanders, F., 1986: Explosive cyclogenesis in the west-central North Atlantic Ocean, 1981-84. Part I: Composite structure and mean behavior. Mon. Wea. Rev., 114, 1781-1794.

_ _ and J. R. Gyakum, 1980: Synoptic-dynamic climatology of the "bomb." Mon. Wea. Rev., 108, 1589-1606.

Schneider, N., and A. J. Miller, 2001: Predicting western North Pacific Ocean climate. J. Climate, 14, 3997-4002.

Seager, R., Y. Kushnir, N. H. Naik, M. A. Cane, and J. Miller, 2001: Wind-driven shifts in the latitude of the Kuroshio-Oyashio Extension and generation of SST anomalies on decadal timescales. J. Climate, 14, 4249-4265.

Small, R. J., and Coauthors, 2008: Air-sea interaction over ocean fronts and eddies. Dyn. Atmos. Oceans, 45, 274-319.

Song, Q., D. B. Chelton, S. K. E. N. Thum, and L. W. O. Neill, 2009: Coupling between sea surface temperature and lowlevel winds in mesoscale numerical models. J. Climate, 22, 146-164.

Stoelinga, M. T., 1996: A potential vorticity-based study of the role of diabatic heating and friction in a numerically simulated baroclinic cyclone. Mon. Wea. Rev., 124, 849-874.

Sutton, R., and P.-P. Mathieu, 2002: Response of the atmosphereocean mixed-layer system to anomalous ocean heat-flux convergence. Quart. J. Roy. Meteor. Soc., 128, 1259-1275.

Sweet, W., R. Fett, J. Kerling, and P. La Violette, 1981: Air-sea interaction effects in the lower troposphere across the north wall of the Gulf Stream. Mon. Wea. Rev., 109, 1042-1052.

Taguchi, B., H. Nakamura, M. Nonaka, and S.-P. Xie, 2009: Influences of the Kuroshio/Oyashio Extensions on air-sea heat exchanges and storm-track activity as revealed in Regional Atmospheric Model Simulations for the 2003/04 cold season. J. Climate, 22, 6536-6560

Tanimoto, Y., S.-P. Xie, K. Kai, H. Okajima, H. Tokinaga, T. Murayama, M. Nonaka, and H. Nakamura, 2009: Observations of marine atmospheric boundary layer transitions across the summer Kuroshio Extension. J. Climate, 22, $1360-1374$

Tokinaga, H., and Coauthors, 2006: Atmospheric sounding over the winter Kuroshio Extension: Effect of surface stability on atmospheric boundary layer structure. Geophys. Res. Lett., 33, L04703, doi:10.1029/2005GL025102.

_, Y. Tanimoto, S.-P. Xie, T. Sampe, H. Tomita, and H. Ichikawa, 2009a: Ocean frontal effects on the vertical development of clouds over the western North Pacific: In situ and satellite observations. J. Climate, 22, 4241-4260.

_ - S.-P. Xie, F. Kobashi, and Y. Tanimoto, 2009b: Local and remote influences of the Kuroshio Extension on the atmosphere. CLIVAR Variations, No. 7, U.S. CLIVAR Office, Washington, D.C., 1-4.

Trenberth, K. E., and J. M. Caron, 2001: Estimates of meridional atmosphere and ocean heat transports. J. Climate, 14, 3433 3443.

Vivier, F., K. A. Kelly, and L. Thompson, 2002: Heat budget in the Kuroshio Extension region: 1993-99. J. Phys. Oceanogr., 32, 3436-3454.

Wai, M. M.-K., and S. A. Stage, 1989: Dynamical analyses of marine atmospheric boundary layer structure near the Gulf Stream oceanic front. Quart. J. Roy. Meteor. Soc., 115, 29-44.

Warren, B. A., 1972: Insensitivity of subtropical mode water characteristics to meteorological fluctuations. Deep-Sea Res., 19, 1-19. 
Willis, J. K., D. Roemmich, and B. Cornuelle, 2004: Combining altimetric height with broadscale profile data to estimate steric height, heat storage, subsurface temperature, and seasurface temperature variability. J. Geophys. Res., 108, 3292, doi:10.1029/2002JC001755.

Worthington, L. V., 1976: On the North Atlantic Circulation. The Johns Hopkins Oceanographic Studies, Vol. 6, Johns Hopkins University Press, 110 pp.

Xie, S.-P., 2004: Satellite observations of cool ocean-atmosphere interaction. Bull. Amer. Meteor. Soc., 85, 195-208.

, T. Kunitani, A. Kubokawa, M. Nonaka, and S. Hosoda, 2001: Interdecadal thermocline variability in the North Pacific for
1958-97: A GCM simulation. J. Phys. Oceanogr., 31, 27982813.

Yasuda, I., 2003: Hydrographic structure and variability in the Kuroshio-Oyashio transition area. J. Oceanogr., 59, 389-402.

Yoshida, A., and Y. Asuma, 2004: Structures and environment of explosively developing extratropical cyclones in the northwestern Pacific region. Mon. Wea. Rev., 132, 1121-1142.

Young, G. S., and T. D. Sikora, 2003: Mesoscale stratocumulus bands caused by Gulf Stream meanders. Mon. Wea. Rev., 131, 2177-2191.

Zhang, R., 2008: Coherent surface-subsurface fingerprint of the Atlantic meridional overturning circulation. Geophys. Res. Lett., 35, L20705, doi:10.1029/2008GL035463. 